\title{
El Hocino de Fuentetovar (Velamazán, Soria). Cogotas I en el oriente de la Submeseta Norte española
}

\section{El Hocino de Fuentetovar (Velamazán, Soria). Cogotas I in the east of the Spanish northern submeseta}

José JAVIER FERNÁNDEZ MORENO

Dirección General de Patrimonio Cultural, Junta de Castilla y León, Avda. Real Valladolid s/n, 47041 Valladolid Email: jjavier.fernandez@jcyl.es

ORCID: https://orcid.org/0000-0002-6904-5237

MARÍA JESÚS TARANCÓN GÓMEZ

Gabinete Arqueológico Arquetipo SCL, C/ Carretera de Logroño 1 Bajo, 42004 Soria Email: arquetipo.scl@telefonica.net

ORCID: https://orcid.org/0000-0002-7451-0789

Agustín RuIZ DE MARCO

Gabinete Arqueológico Arquetipo SCL, C/ Carretera de Logroño 1 Bajo, 42004 Soria Email: arquetipo.scl@telefonica.net

ORCID: https://orcid.org/0000-0002-7182-8898

MONTSERRAT LERÍN SANZ

Gabinete Arqueológico Arquetipo SCL, C/ Carretera de Logroño 1 Bajo, 42004 Soria

Email: arquetipo.scl@telefonica.net

ORCID: https://orcid.org/0000-0002-6773-7539

RAQUEL BARRIO ONRUBIA

Gabinete Arqueológico Arquetipo SCL, C/ Carretera de Logroño 1 Bajo, 42004 Soria Email: arquetipo.scl@telefonica.net

ORCID: https://orcid.org/0000-0002-0681-1010

ÓSCAR ARELLANO HERNÁNDEZ

Gabinete Arqueológico Arquetipo SCL, C/ Carretera de Logroño 1 Bajo, 42004 Soria Email: arquetipo.scl@telefonica.net

ORCID: https://orcid.org/0000-0003-4510-149X

Recibido: 15/04/2019. Aceptado: 14/05/2019. 
Cómo citar: Fernández Moreno, José Javier, Tarancón, María Jesús, Ruiz de Marco, Agustín, Lerín, Montserrat, Barrio, Raquel y Arellano, Óscar (2018): "El Hocino de Fuentetovar (Velamazán, Soria). Cogotas I en el oriente de la Submeseta Norte española”. BSAA arqueología, LXXXIV, pp. 94-133.

DOI: https://doi.org/10.24197/ba.LXXXIV.2018.94-133

Resumen: Se presenta un nuevo asentamiento de los denominados "campos de hoyos" de la Edad del Bronce del interior peninsular. Aun cuando las estructuras negativas aparecen muy arrasadas, es posible identificar una diversa tipología que confirma actividades vinculadas a la explotación de recursos naturales por un grupo que utilizaba cerámicas típicas de Cogotas I. La comparación tipológica y decorativa de los materiales cerámicos reclama su evolución desde grupos de amplio arraigo en el territorio, cuestionando la vinculación de la técnica excisa a influencias foráneas, rastreando su presencia desde la fase formativa del grupo, junto con la incisión y el boquique, singularmente en el oriente de la Submeseta Norte.

Palabras clave: Península Ibérica, Alto Duero, Edad del Bronce, Cogotas I, "campos de hoyos".

Abstract: This article presents a new settlement of the typical sites of the lowland pits of the Bronze Age of the peninsular interior. Although the negative structures are very devastated, it is possible to distinguish different typologies that confirm the activities related to the exploitation of natural resources by a group that uses the typical ceramic Cogotas I. The typological and decorative comparison of the materials points to an evolution from that of groups deeply rooted in the territory, and questioning the dependence of the technique excised to foreign influences, tracking its presence from the formative phase of the group, together with the incision and the stab-and-drag, singularly in the East of the Meseta.

Keywords: Iberia, Meseta, Bronze Age, Cogotas I, Lowland

\section{INTRODUCCIÓN}

El estudio ${ }^{1}$ de Evaluación de Impacto Ambiental para la construcción de una explotación pecuaria en el paraje de El Hocino, en la localidad de Fuentetovar (Velamazán, Soria) determinó, entre las medidas correctoras, la ejecución de un conjunto de sondeos estratigráficos y control arqueológico que valoraran la posible afección de la construcción en el inmediato yacimiento arqueológico conocido con los topónimos de Torremocha / La Torrecilla.

El enclave se ubica en un pequeño altozano, inmediato a la finca en la que se pretendía construir la granja porcina donde se tenía conocimiento de un

\footnotetext{
${ }^{1}$ Se realizaron distintas actuaciones por la empresa Arquetipo: Arellano et alii, 2015: Estudio previo de afección al Patrimonio Cultural, Arqueológico, Etnológico e Histórico. Prospección Arqueológica Intensiva del proyecto de cebadero porcino en el paraje El Hocino, (Fuentetovar, Soria); Ídem, 2016: Sondeos arqueológicos de comprobación. Cebadero porcino, en El Hocino”, (Fuentetovar, Soria); Ídem, 2018: Control Arqueológico de las obras de Cebadero Porcino, en "El Hocino" Fuentetovar, Soria. Todos informes inéditos depositados en el Servicio Territorial de Cultura de Soria.
} 
despoblado de la Comunidad de la Villa y Tierra de Berlanga (Martínez, 1983) y su necrópolis ${ }^{2}$ (Casa, 1992: 384) que pudo establecerse al amparo de una construcción defensiva, una torre o atalaya medieval, cuya única evidencia hasta el momento es el topónimo con el que se conoce el lugar. La prospección de este paraje para la realización de la Carta Arqueológica de Almazán (Revilla, 1985), aportó, como novedad, el hallazgo superficial de algunas cerámicas atribuidas a un momento inicial de la Edad del Bronce. Posteriores trabajos arqueológicos, vinculados también con expedientes de Impacto Ambiental, no concluyeron con una información más precisa ${ }^{3}$.

La finca objeto de estudio se sitúa en la margen izquierda del Duero. Tiene una pendiente uniforme de aproximadamente el 3\% ascendente del lindero sur hacia el norte, punto más alto de la parcela por donde discurre la obra hidráulica de la acequia 04 del Canal de Almazán.

El entorno circundante se caracteriza por un relieve llano, con una altitud media de $925 \mathrm{~m}$, con elevaciones que crean una sucesión de suaves lomas. Pertenece a la unidad morfoestructural de Almazán, en la mitad occidental de la fosa que lleva el mismo nombre, la cual aparece surcada en todo su recorrido por el río Duero (Fig. 1). Éste discurre por una vega no excesivamente encajada que, en épocas recientes, aparece ocupada indistintamente por cultivos de secano destinados al aprovechamiento de cereal y de regadío que definen un paisaje agrario, salpicado por árboles aislados y por alineaciones de vegetación arbórea y arbustiva coincidiendo con los arroyos de drenaje. Geológicamente la zona está ocupada por terrenos cuaternarios, correspondientes a las llanuras de acarreos del río Duero en la zona más cercana al cauce.

\section{LA INTERVENCIÓN ARQUEOLÓGICA}

Para poder evaluar el impacto de la obra ${ }^{4}$ sobre los restos arqueológicos, en 2015, se efectuó la prospección intensiva y de cobertura total y, en 2016, se

\footnotetext{
${ }^{2}$ Durante la mejora del camino rural que discurre al norte de la finca, se confirmó la existencia de la necrópolis con la documentación de, al menos, ocho tumbas de lajas datadas en época bajomedieval-moderna. Distribuidas alrededor de un grueso muro, probablemente correspondientes a la iglesia de este lugar (Arellano et alii., 2017: Documentación de la necrópolis de La Torrecilla localizada en el camino CNT 7-5, incluido en el proyecto de infraestructura rural en la zona de C. P. del Canal de Almazán (Fuentetovar, Soria). Informe inédito depositado en el Servicio Territorial de Cultura de Soria.

${ }^{3}$ En el entorno más inmediato de la finca 73 del polígono 6 se han llevado a cabo intervenciones arqueológicas vinculadas a las distintas fases de mejora del Canal de Almazán y modificación de caminos rurales, en los años 2007, 2008, 2013 y 2015 Todas ellas cuentan con sus respectivos informes, inéditos, depositados en el Servicio Territorial de Cultura de Soria.

${ }^{4}$ Todos estos trabajos arqueológicos y los que describiremos a continuación fueron financiados íntegramente por el promotor de la explotación porcina D. Álvaro Moreno Molina.
} 
realizaron treinta y seis sondeos (S) manuales de comprobación y seis transects (T) mecánicos que afectaron a una superficie de $124 \mathrm{~m}^{2}$ distribuidos en la superficie afectada, $983 \mathrm{~m}^{2}$, por la construcción porcina.

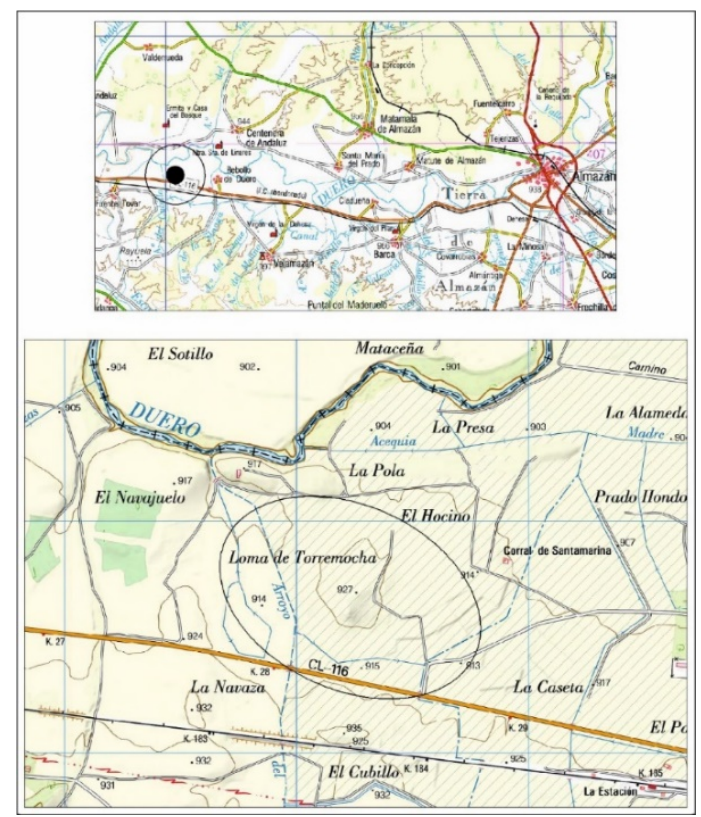

Fig. 1. Detalle de la localización del lugar de El Hocino/Torremocha de Fuentetovar a partir de mapa 1:25.000 del IGM Hoja 406 (Almazán).

Únicamente en S7 y S12 aparecieron algunos fragmentos cerámicos realizados a mano, y en el T1 se recuperaron algunos objetos dispersos de época medieval y otros de cronología prehistórica, pero no se identificó ninguna estructura de ocupación con las que asociarlos.

Con estos resultados se definió la compatibilidad de la construcción de las naves proyectadas con la condición de alejarla de la loma en la que se habían identificado los elementos medievales. No obstante, y ante la posibilidad de que pudieran aflorar evidencias no detectadas en superficie y/o fuera de las zonas directamente sondeadas, como medida correctora de protección y cautela, se propuso y aprobó en el Estudio de Impacto Ambiental, hacer un control arqueológico de todos los movimientos de tierra, con la subsiguiente documentación y estudio de los restos que pudieran aparecer. Éste, efectuado en 2017, aportó las primeras evidencias estructurales, muy arrasadas, confirmado la existencia del asentamiento prehistórico. 


\section{RESULTADOS DE LOS TRABAJOS ARQUEOLÓGICOS}

\subsection{Secuencia de la ocupación}

La secuencia estratigráfica verificada durante el control ratificó la documentada en los sondeos previos. Sin solución de continuidad, se superponen el exiguo manto vegetal, el nivel de arada y el estrato geológico. Desde el punto de vista litológico apenas se advierten diferencias en ninguno de los estratos, estando caracterizado el depósito sedimentario por tierra de textura arenosa, color marrón-rojizo y compactación media, carente de intrusiones, con un desarrollo muy uniforme y homogéneo por toda la finca. Bajo él se disponen las finas arcillas y limos rojizos que constituyen la base geológica del yacimiento.

La única excepción se advierte en la parte superior de la finca, justo debajo de la cota mayor, donde se identificó en la campaña de 2016 una alineación de roca calcárea, de tono amarillento, que aflora en algunos casos en la capa de limos. Aparece en forma de lentejones, de superficie irregular y erosionada, producto del recubrimiento de la roca por el sedimento rojizo (Fig. 2). Esta curiosa formación está identificada en el Mapa Geológico Nacional (Ferreiro, 1991: 17) como un afloramiento de dolomías cretácicas, concretamente coniacienses-santonienses, en el techo del Cretácico Superior que ocupan toda la superficie entre la terraza por la que discurre el Duero y la actual carretera comarcal. Se trata de rocas secundarias que afloran puntualmente en la cuenca terciaria de Almazán, correspondiendo a una estructura anticlinal con origen en el plegamiento de la cobertera secundaria, probablemente exhumada tras el desmantelamiento de los materiales terciarios que la cubrían debido a la labor erosiva del Duero y sus afluentes. La Memoria del Mapa Geológico ya referida, especifica que estas dolomías en bancos están finamente estratificadas con laminación algar y superficies ferruginizadas, a las que siguen dolomías oquerosas con geodas, masivas, que tienen mucho protagonismo morfológico ${ }^{5}$. Una característica intrínseca de estas formaciones, a considerar para lo que nos ocupa, es la habitual presencia derivada de travertinos calcáreos en los alrededores de los afloramientos dolomíticos, $\mathrm{y}$, asociados, las formaciones de toba $^{6}$ y la abundancia de fuentes y manantiales de aguas de calidad.

\footnotetext{
${ }^{5}$ Queremos agradecer a M. Martínez Arnaiz, del Departamento de Geografía de la UBU, la ayuda y sugerencias para caracterizar e interpretar estos afloramientos; también los comentarios de Alfredo Pérez, del CENIEH, sobre la geológica del lugar y su previsible evolución.

${ }^{6}$ El nombre de la localidad de Fuentetovar fue elegido en la década de los años cincuenta del siglo pasado para sustituir al anterior de Fuentelpuerco. Por la información disponible la Real Academia de la Historia propuso la nueva denominación en detrimento de otras alternativas, retomando el de un antiguo señorío de los duques de Frías, según se detalla en: http://diariodelahistoriasoriana.blogspot.com.es/2016/05/de-fuentelpuerco-fuente-tovar.html. Pese
}

BSAA arqueología, LXXXIV, 2018, pp. 94-133.

E-ISSN: 2530-6367 
En el rebaje de la capa vegetal no se localizó ningún resto o evidencia constructiva, ni de época histórica ni prehistórica, identificándose, diseminados a lo largo de toda la superficie afectada, apenas un centenar de utensilios de tres momentos diferentes: el medieval, otro romano y el prehistórico ${ }^{7}$.

El nivel intermedio de la excavación no fue mucho más fructífero, excepción en la zona media y baja, donde se identificaron un total de dieciocho cubetas -denominadas durante el seguimiento como evidencias (EEVV)-, estructuras negativas con contenidos orgánicos o de cultura material. Se procedió a su rebaje y excavación manual, confirmándose que se encontraban apoyadas directamente sobre el nivel sedimentario que constituye la base geológica.

Finalmente, como se ha señalado, se localizaron algunos materiales prehistóricos depositados en las oquedales de los afloramientos calcáreos descubiertos en S12, y que, por la ubicación y su singularidad, hay que suponer se sitúan en posición primaria, directamente sobre estas rocas que, por ello, debían ser visibles durante la ocupación prehistórica del lugar (Fig. 2).

\subsection{Las estructuras negativas}

Todas las cubetas presentan un patrón uniforme caracterizado por su morfología de planta circular o elipsoidal de variada amplitud. Predominan los fondos de sección cóncava o con la base más o menos plana, y paredes ligeramente convexas. Desconocemos su altura original pues solo se ha documentado el extremo inferior de las cavidades, con un alzado que oscila de escasos centímetros -prácticamente a nivel del corte- hasta un máximo de $23 \mathrm{~cm}$ en la EV18.

De forma general, todos los interfaciales negativos están sellados por un único relleno bastante homogéneo en cuanto a textura, composición y coloración, sin estratificación de vertidos, que destaca sobre el sustrato limosoarenoso del manto natural.

En su excavación se diferenció un grupo de cubetas amortizadas con un sedimento de textura arenosa, de tono marrón-negruzco, cuya matriz contenía cantos cuarcíticos de pequeño-fino calibre y materia orgánica disgregada, frente a otro conjunto, colmatadas por un depósito de composición arenosa que porta

\footnotetext{
a ello no deja de ser llamativo la coincidencia del mismo con la más que presumible abundancia, en la zona, de piedra toba y fuentes, algunas de las cuales son destacadas en la encuesta del Catastro del Marques de la Ensenada o en el Diccionario Geográfico-Estadístico-Histórico de España de Pascual Madoz.

7 Los restos de cultura material recuperados fueron signados con el número asignado por el Museo Numantino, donde finalmente se han depositado. Agradecemos a su directora, Dña. Marian Arlegui, las facilidades dadas para el estudio y las fotografías facilitadas de otros fondos.
} 
trazas cenicientas, briznas de carbón y de madera, en ese caso, de color grisáceo y/o negruzco. Respecto de su contenido, como es frecuente en este tipo de estructuras, se limita a fragmentos cerámicos (EEVV 1, 6, 7, 12, 13, 16, 17 y 18) o líticos (un único resto en la EV4), cuyo análisis y contextualización se aborda en el siguiente apartado.

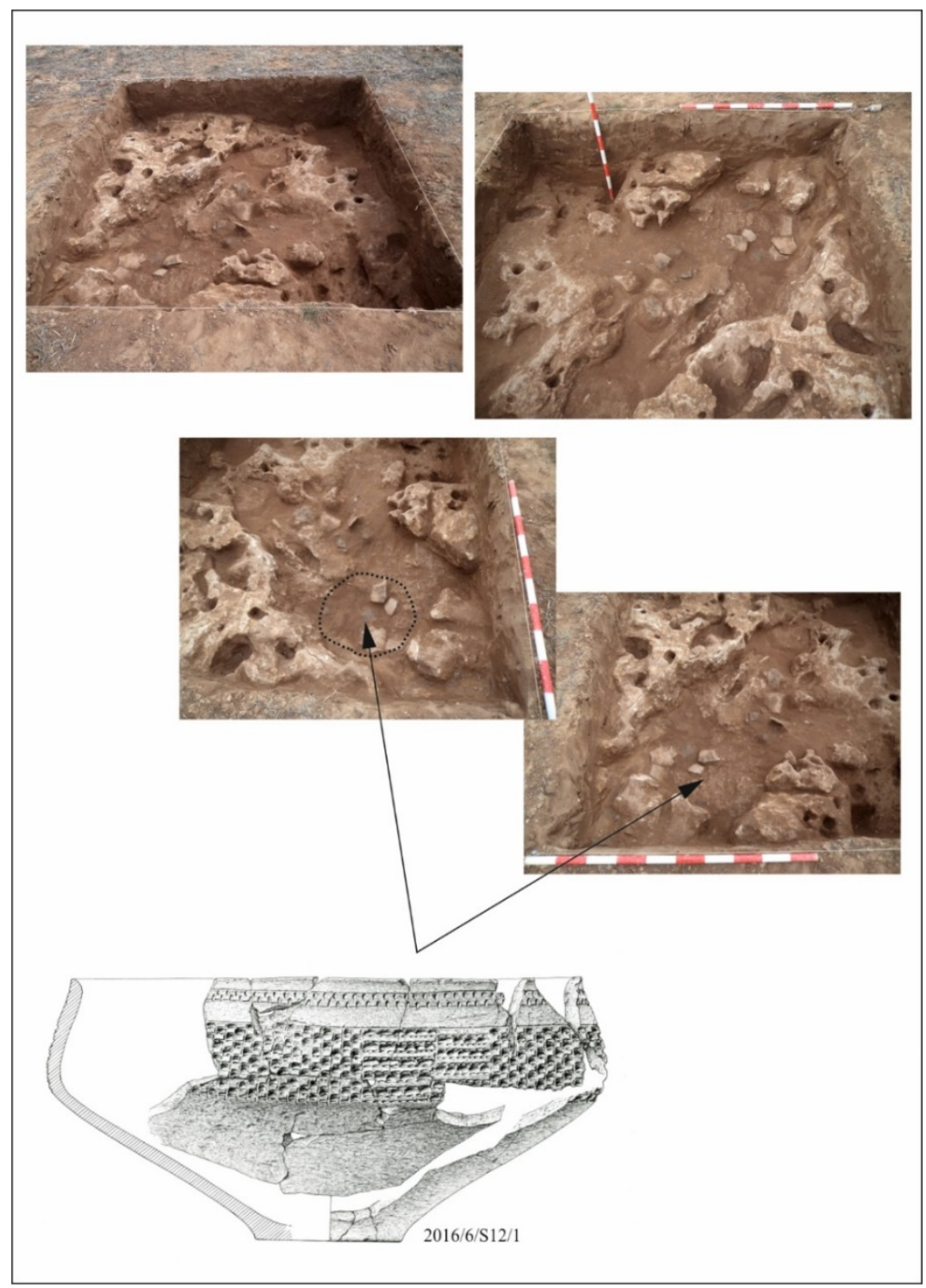

Fig. 2.- Sondeo 12. Lugar del hallazgo de la cazuela entre las formaciones calcáreas. 
Dejando al margen EV1 que contenía exclusivamente materiales de época romana, el resto de evidencias son de clara atribución prehistórica. La casualidad ha motivado que los porcentajes obtenidos en cada una de las tipologías atribuidas a la primera ocupación del yacimiento sean muy parejas (Fig. 3).

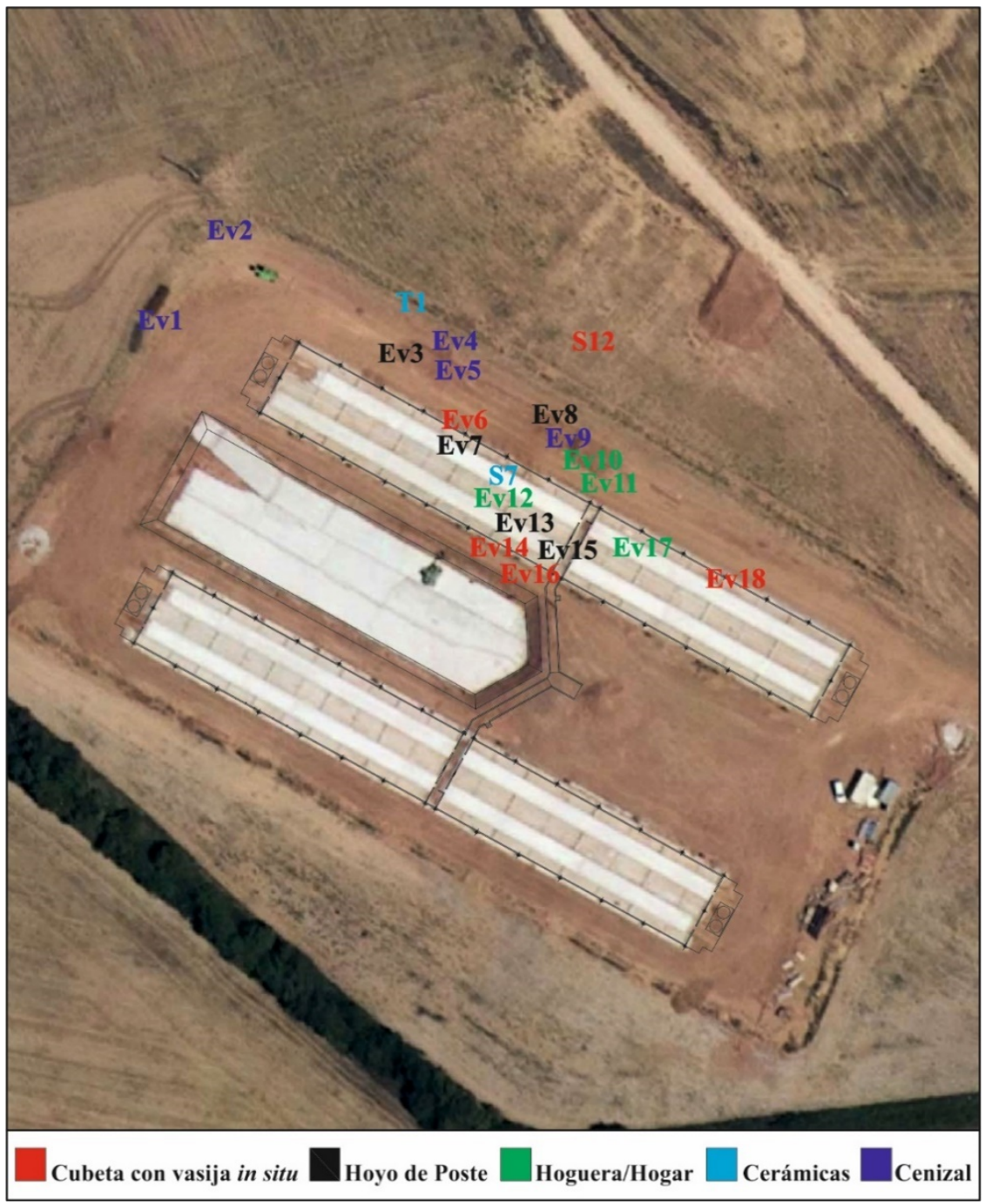

Fig. 3.- Localización de las distintas evidencias identificadas. 
El grupo más numeroso lo constituyen los cinco hoyos (EEVV 3, 7, 8, 13 y 15) que se han identificado como agujeros de poste, principalmente, por sus rasgos morfológicos: plantas circulares o elipsoidales y evidentes secciones cóncavas o, en su defecto, rectilíneas. Respecto del tamaño de sus diámetros, siempre referidos a la cota generada desde el corte efectuado por la maquinaría, oscila desde los $14 \mathrm{~cm}$ a los $28 \mathrm{~cm}$ (Fig. 4). En general, la matriz sedimentaria de esos cinco agujeros carece de intrusiones, si bien se identifican briznas de carbón y/o ceniza que, generalmente, se vinculan a la descomposición de la madera que albergarían en su interior. Sólo en dos de esas cavidades (EEVV 7 y 13) se recuperaron fragmentos cerámicos elaborados a mano. Grosso modo, se asume su funcionalidad como hoyos de poste para la sustentación del armazón de distintos elementos "constructivos", asimilados a espacios habitacionales (fondos de cabaña, hogar,...) o con los destinados a la actividad económica (cercados para el ganado, áreas de almacenaje, talleres, cortavientos, etc.).

Otras cinco (EEVV 1, 2, 4, 5 y 9) constituyen un segundo grupo de cubetas amortizadas con un depósito de cenizas, muy finas, carente de intrusiones de otro tipo, ni piedras, ni huesos ni cerámica -a excepción de EV4 que cuenta con el único fragmento lítico, y recordando que EV1 contenía materiales de amortización adscritos a época romana-. Genéricamente se vienen denominando cenizales por considerar que esta función parece más precisa que la de basureros pues, aun asumiendo que todos los usos tipificados en este yacimiento llevan implícito que se corresponden con acciones antrópicas de abandono de desechos, aquí es la cenicienta la matriz que contienen. Desde el punto de vista morfológico, apenas difieren del resto: planta elipsoidal y sección de tendencia cóncava o rectangular con las paredes de ascenso cóncavo. Las dimensiones son mayores que las atribuidas a los hoyos de poste. En estos casos, oscilarían con ejes superiores al metro, tanto de longitud como de anchura (EV4) y en las de tamaño menor (EEVV 2, 5 y 9) los ejes alcanzaran la mitad de tamaño que aquellas. Todas presentan una escasa altura, sin que lleguen a alcanzar los 20 cm (Fig. 4).

Junto a esos lentejones cenicientos hay otros cuatro contenedores (EEVV $10,11,12$ y 17) cuyo patrón morfológico y medidas son similares a los anteriores pero, al aparecer sus respectivos entalles quemados y/o ennegrecidos por la acción del fuego, se han consignado como hoguera/hogar. Frente a los cenizales comentados, estas estructuras ofrecen colmataciones de color negro que contienen briznas de carbón, ceniza, cuarcitas de fino calibre -algunas de ellas quemadas al formar parte de la combustión- y, de forma dispersa y disgregada, algunas pellas de arcilla y materia orgánica. Sobresale la EV17, diferenciada de los otros hogares abiertos, aunque todos debieron de funcionar como hogares al aire libre. En este caso, está enmarcado por numerosos 
guijarros, de pequeño-mediano tamaño, ennegrecidos y quemados por efecto del fuego, formando un cerco, de entre $18-22 \mathrm{~cm}$ de ancho por $10 \mathrm{~cm}$ de alto. Ese perímetro genera un espacio interior, de $50 \mathrm{~cm}$ diámetro, donde alojar el lar propiamente dicho. En el extremo oeste se advierte un carbón encajado entre las piedras, de $7 \mathrm{~cm}$ de diámetro, que corresponde a un leño sobre el que se interrumpió la combustión (Fig. 4).

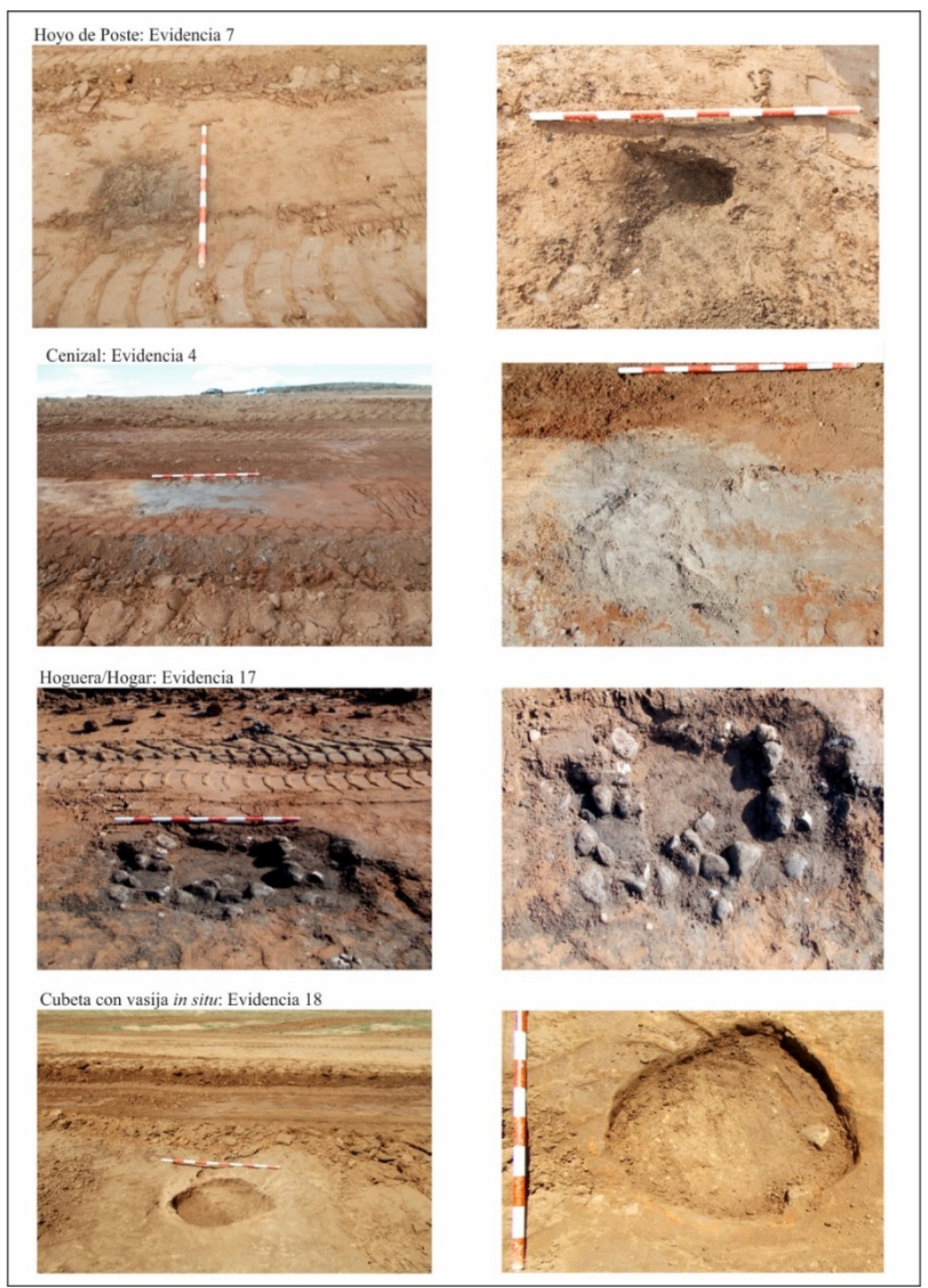

Fig. 4.- Ejemplos de la tipología de las evidencias identificadas. 
Con cinco ejemplares se documentan las denominadas "cubetas con vasija in situ" o "contenedores de vasijas" (S12; EEVV 6, 14, 16 y 18). Se trata de hoyos de planta elipsoidal con ejes entre $86 \mathrm{~cm}$ y $30 \mathrm{~cm}$ y sus alzados presentan medidas de escasos centímetros a máximos de $23 \mathrm{~cm}$. En las matrices de sus respectivos depósitos de colmatación se recuperaron numerosos restos cerámicos elaborados a mano, de mediano o gran tamaño, asentados en el terreno y adaptados a la morfología de la cavidad que la contiene. Destaca de manera excepcional la cubeta EV18, primero por el entalle negativo, marcado por un reborde de arcilla bien depurada, de escasa consistencia y endurecida, sin quemar. Si su presencia fue palpable tras el corte horizontal de la traílla, no resultó tan evidente durante su excavación manual al ser imposible mantener in situ sus paredes (Fig. 4). También lo fue por su contenido, seis fragmentos cerámicos de mediano tamaño, de los cuales tres disponen decoraciones típicas de la Edad del Bronce, similares a las recuperadas en el S12, como se detallará más adelante.

\subsection{El material arqueológico}

Llama la atención el escaso material arqueológico recuperado en relación con el volumen de tierra removido. Los trabajos apenas han deparado tres centenares de hallazgos en una superficie total de $17.000 \mathrm{~m}^{2}$ en la que se removió algo más de $8.800 \mathrm{~m}^{3}$. El $90 \%$ son de atribución prehistórica; el 10\% restante corresponde a cerámicas y un hierro de atribución romana y medieval casi en igual proporción, 18 y 15 restos respectivamente. Los prehistóricos, 280 piezas, son cerámicos a excepción de tres líticos. La mitad de ellos, 136, se localizaron en el interior de las estructuras negativas y el resto en el nivel de sedimentación, tanto en el de arada como en el de sellado de las cubetas.

Este patrón de distribución se reitera en el caso de los materiales de atribución romana -se identificaron en EV1- pero no los de época medieval que solo se recuperaron en los niveles superficiales removidos. Por tanto, parece confirmarse que el asentamiento más moderno se localiza en la parte superior de la loma, mientras que las dos ocupaciones más antiguas debieron situarse en la base de la pequeña elevación, en la cuenca de inundación.

Centrándonos en los materiales prehistóricos, hay que destacar algunas piezas diagnósticas y siete cerámicas que muestran decoración incisa, de boquique y excisión, de acuerdo a la siguiente distribución y características, atendiendo al momento en el que se recuperaron: 


\subsubsection{Campaña de 2016}

Durante estos trabajos se identificaron las primeras cerámicas en posición original. En el rebaje del S7 se recuperó un fragmento perteneciente a un borde recto de labio plano (2016/6/S7/2) y el extremo distal de un cincel (2016/6/S7/1) realizado sobre roca metamórfica de clara procedencia exógena (Fig. 5).

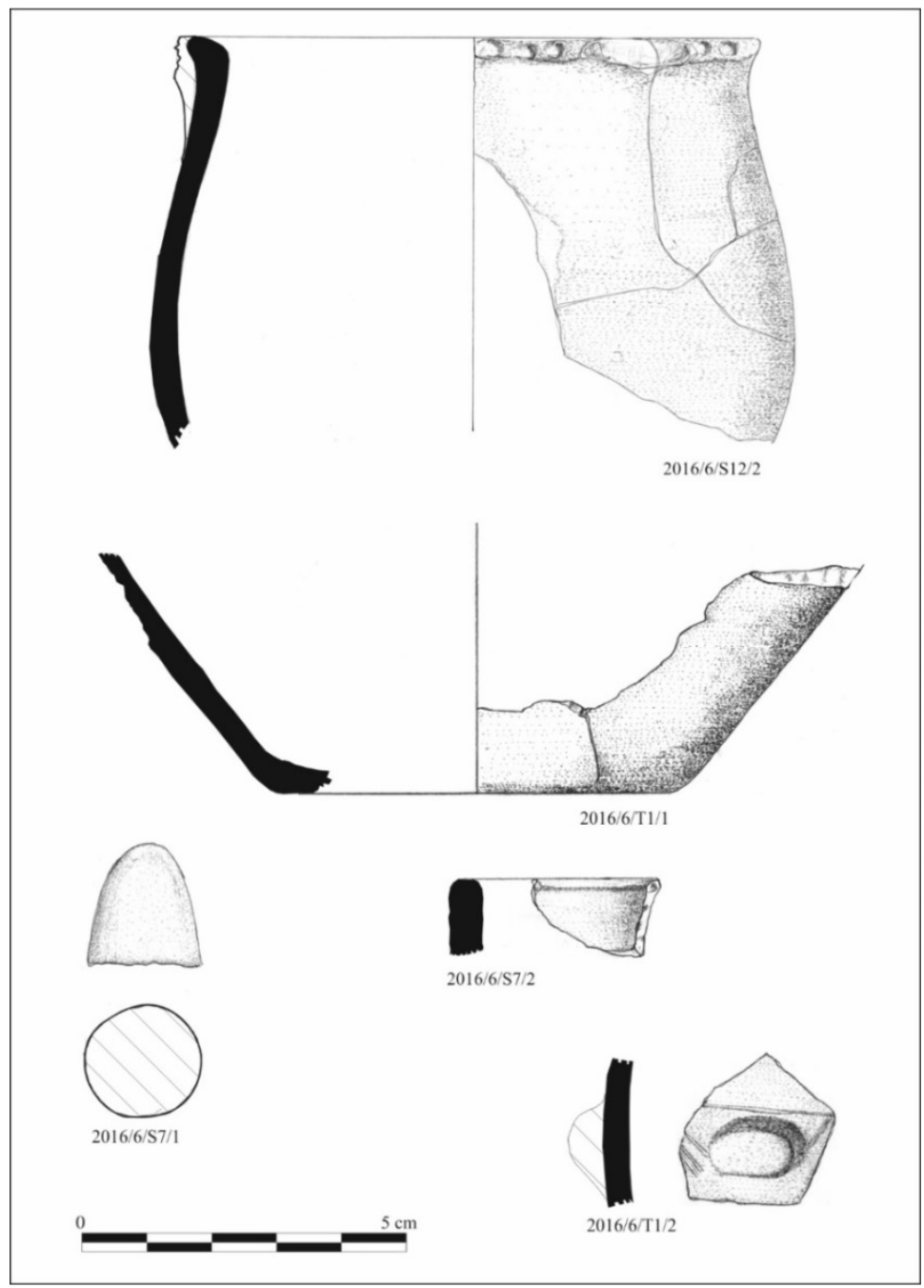

Fig. 5.- Materiales más representativos recuperados en la campaña 2016. 
En el S12, en una oquedad de la dolomía de base, se recuperaron 59 fragmentos que corresponden a dos vasos distintos: una olla de perfil en "S" (2016/6/S12/2), reconstruida con seis fragmentos, con labio exvasado y dígitoungulado con la huella de un antiguo mamelón desaparecido (Fig. 5); y una gran cazuela (2016/6/S12/1) que suponemos completa, a la que pertenecen 53 fragmentos que aparecieron agrupados en su interfacial y evidencian su ubicación in situ (Fig. 6). Se trata de un gran contenedor abierto, una gran cazuela, de perfil carenado, que presenta, sobre la carena y cuello, una profusa decoración realizada mediante la combinación de tres técnicas: incisión, boquique y excisión. Es una pieza de aspecto proporcionado, paredes ligeramente gruesas en el borde, de pasta cuidada con desgrasante fino y medio, con superficies pulidas de color oxidante. En cuanto a la forma, destaca su perfil troncocónico, definido por una carena hacia la parte media del perfil, que coincide con la máxima anchura del vaso $(40 \mathrm{~cm}$, siendo $36,5 \mathrm{~cm}$ el diámetro en la boca) y divide la pieza en dos partes. La inferior (8 cm de los $19 \mathrm{~cm}$ de altura total) tiene las paredes rectas que rematan un pequeño resalte para enlazar con el fondo plano (10,5 cm de diámetro). La parte superior $($ de $11 \mathrm{~cm})$ desarrolla un alto cuello de paredes rectas entrantes cuyo extremo se redondea para conformar el borde del vaso. Sin duda, la cazuela destaca por su ornamentación que la enmarcaría entre las cerámicas de Cogotas I. Aunque no se concluyó la reconstrucción física de la cazuela ${ }^{8}$, ésta y la proyección de los fragmentos recogidos permiten hacernos una idea detallada de la totalidad del esquema decorativo. Una estrecha banda corrida que se muestra equidistante entre el borde y una amplia cenefa continua que ocupa toda la parte superior hasta sobrepasar el borde inferior de la carena.

La banda superior se inicia a poco más de $2 \mathrm{~cm}$ del labio, tiene una anchura media de $1 \mathrm{~cm}$ y está delimitada por sendas líneas incisas realizadas con punzón que deja un surco de $2 \mathrm{~mm}$ de anchura. Desde ambos extremos se ha impreso una fina punta triangular que penetra entre $4-5 \mathrm{~mm}$ y se aplica contrapuesta, generando un típico motivo en zigzags, pseudoexciso, aunque técnicamente correspondería a una impresión, muy común entre los motivos Ciempozuelos.

Debajo de esta banda y con una separación que oscila entre 1-1,3 cm se inicia la cenefa que ocupa una anchura de entre 5,6-6 cm, alcanzando la parte inferior de la carena. La distribución de los motivos y la huella del enmarcado de las bandas y metopas denuncian la existencia de una planificación previa. La cenefa se divide en metopas que alternan espacios decorados con excisión, tanto de retícula en ajedrezado como en bandas de rectángulos o pastillas alargadas que resaltan por el vaciado de la pasta de los espacios alternos.

\footnotetext{
${ }^{8}$ La reconstrucción básica se realizó durante los trabajos de campo a fin de identificar el esquema decorativo y realizar su estudio. Está pendiente la restauración definitiva en el Museo Numantino. El dibujo se debe a D. Ángel Rodríguez González.
}

BSAA arqueología, LXXXIV, 2018, pp. 94-133. E-ISSN: 2530-6367 


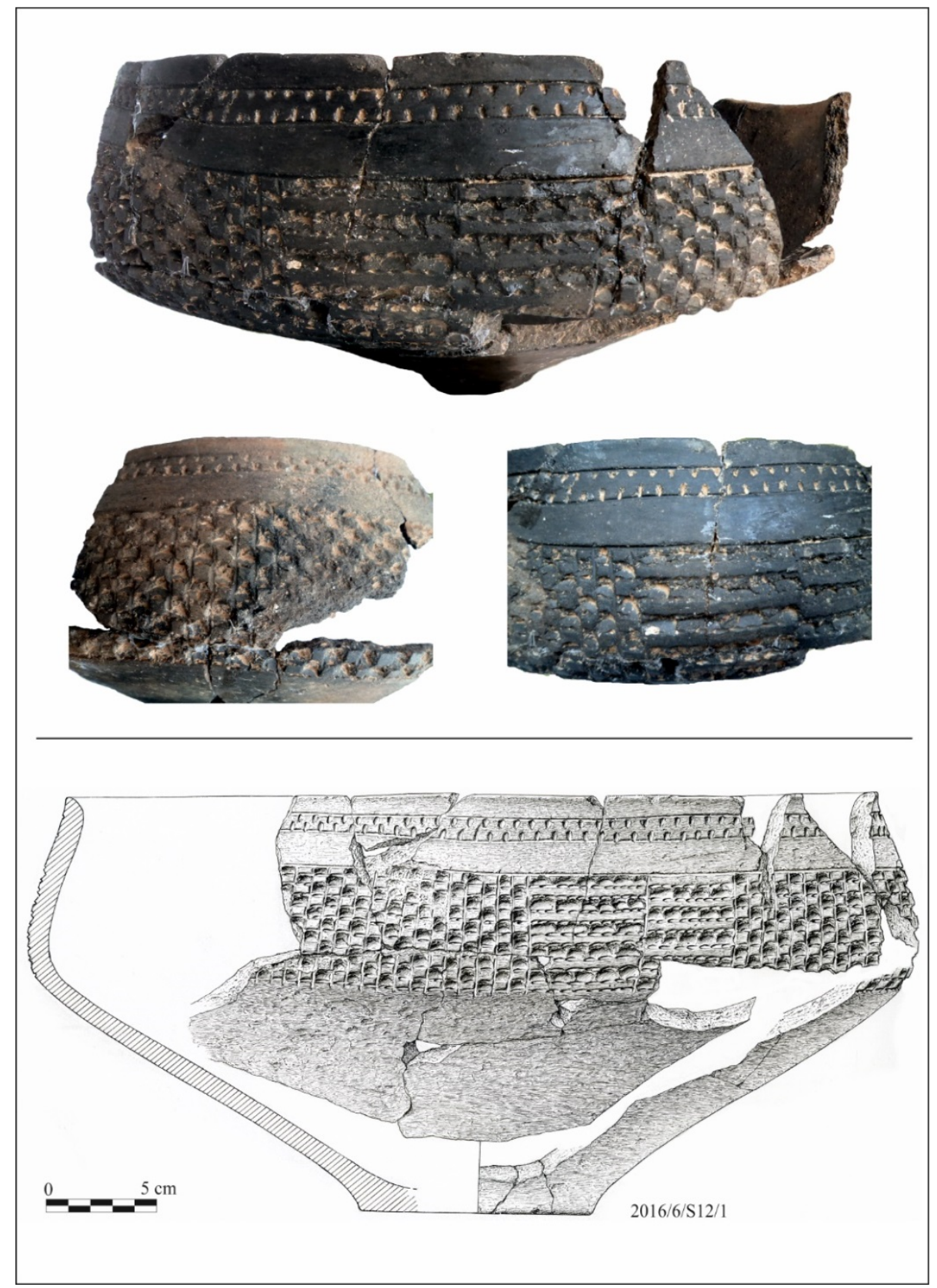

Fig. 6.- Cazuela con decoración mixta. Sondeo 12. 
El límite superior de ésta cenefa fue delimitado por una línea incisa similar a la de la cenefa superior si bien, posteriormente, al desarrollar el resto de la decoración se superponen, ocasionalmente, aplicaciones de boquique que refuerzan la delimitación en aquellos espacios en los que se extrajo pasta. La línea inferior de la cenefa está realizada con la técnica de boquique, para lo que probablemente se empleó, por la similitud de las huellas en todo un vaso, un mismo punzón que se aplicó con la pasta fresca, en "estado de cuero", dado que la huella es profunda y larga, de unos $6 \mathrm{~mm}$, y realizada de izquierda, punto, a derechas, raya.

Una vez delimitada esta cenefa principal, se procedió a su compartimentación en metopas, suponemos que agrupadas en conjuntos repetitivos, de motivos alternos: ajedrezado y espacios de bandas resaltadas. El número y tamaño de las metopas no respetan un mismo ritmo, si bien el tamaño de las agrupaciones, tomando como referencia la parte remontada, tiene una misma anchura. Así, se iniciaría con una metopa de retícula ajedrezada (A) y otra doble de bandas (B) resaltadas alternas, con una anchura total de $20,8 \mathrm{~cm}$ que resulta de la suma de los parciales $(A+(B+B))$ de $11+5,3+4,5 \mathrm{~cm}$, respectivamente. La siguiente agrupación estaría compuesta por una banda de ajedrezado más tres de rectángulos alternos. Esto es, la de ajedrezado es ligeramente más ancha y las otras se dividen -en este bloque- en tres más pequeñas $(A+(B+B+B))$ que, en conjunto, ocupan los mismos $20,8 \mathrm{~cm}$, cociente que resulta de la suma ahora de las cuatro $11,3+3,5+3,5+2,5 \mathrm{~cm}$, en el orden mencionado. Por tanto, la superficie del vaso fue dividida intencionadamente en tres bloques iguales sobre los que distribuyó posteriormente los mismos motivos pero con ligeras variantes en el tamaño y combinación. En cualquier caso, se evidencia la preparación y diseño previo, lo que indica un interés y cuidado en el desarrollo compositivo.

Todas las líneas verticales de separación se han realizado mediante una incisión que deja una línea del mismo tamaño que las ya descritas, unos $2 \mathrm{~mm}$ de anchura, mientras que todas las líneas horizontales tienen huellas de boquique, aun cuando puede haber existido, por algunas trazas, un esbozo inciso previo.

La metopa del ajedrezado se retículo en diez bandas horizontales con separación entre 6,2 y $9 \mathrm{~cm}$, y ocho bandas verticales más regulares, de unos 0,8 $\mathrm{cm}$, que dejan un damero de cuadrados alternos de entre 6 a $8 \mathrm{~mm}$ de lado. La extracción de los cuadros negativos se realizó mayoritariamente desde la línea inferior con una pequeña espátula, aprovechando el relieve creado por el boquique que delimita las líneas horizontales. El interior de la mayoría de estos espacios resulta intencionadamente rugoso.

En cuanto a las bandas rectangulares alternas, la técnica fue similar. Una vez delimitadas, mediante líneas efectuadas con la técnica del boquique, se 
procedió a la extracción de la pasta de los espacios negativos alternos. En las metopas, el número de bandas es idéntico, cinco, con una superficie resaltada que oscila entre los 4-6 mm, alternando banda en relieve y la negativa en el inicio y final en cada metopa. En los espacios negativos, como anteriormente en los de los ajedrezados, se advierte un relieve irregular que hay que suponer estaba destinado a recoger algún tipo de pasta de distinto color que destacaría el motivo decorativo y que da sentido a la utilización de estas técnicas, aunque en la pieza que nos ocupa no ha podido confirmarse el recubrimiento ${ }^{9}$.

Finalmente en el T1, abierto en la misma campaña, mezclados con materiales más modernos, se identifica un fondo plano de paredes salientes, rectas (2016/6/T1/1), y un fragmento de pared con mamelón trapezoidal, enmarcado por líneas incisas oblicuas que no permiten mayor precisión (2016/6/T1/2) (Fig. 5).

\subsubsection{Campaña de 2017}

En los niveles superiores del rebaje del terreno se recogieron ciento un fragmentos atribuidos a la ocupación más antigua. La mayoría son piezas rodadas y muy fragmentadas que no permiten presión alguna, salvo tres cerámicas que tienen distinta decoración realizada con técnica de boquique e incisa. Éstas muestran similitudes técnicas de cocción y tratamiento similares con las anteriores (Fig. 7). Una de ellas (2017/5/R/1) corresponde al borde recto de labio redondeado decorada, bajo la línea del borde, con una línea de cosido simple incisa y otra banda inferior con boquique trazada de derecha a izquierdas, de la que arranca otra oblicua indeterminada. Otra (2017/5/R/2) es un fragmento de galbo poco rodado, con decoración de doble línea horizontal con boquique, en la misma dirección. De la inferior penden trazos oblicuos incisos. La tercera (2017/5/R/3) es otro pequeño fragmento de pared, en la que se desarrolla un motivo formado por triángulos rellenos de punteados y enmarcados en la parte superior por doble alineación, realizado con boquique en dirección contrapuesta, desde la parte inferior a la superior del ángulo (Fig. 7). Además de estas cerámicas, en el decapado de la explanación perimetral de las naves, se recogieron varios bordes salientes de pequeños vasos de paredes verticales alisadas, con cocciones tanto oxidantes como reductoras o mixtas, y, como todo el conjunto, con desgrasantes de tamaños finos y medios de cuarcita,

\footnotetext{
${ }^{9}$ Los análisis se realizaron en el laboratorio del Centro de Conservación y Restauración de Bienes Culturales de Castilla y León: "Caracterización de materiales de la cazuela cerámica de Fuentetovar” N.G.R. 555. Según el informe, la cerámica se coció a una temperatura entre $650^{\circ}$ y $800^{\circ}$ y no es concluyente con la identificación de otro material distinto al de la constitución de la propia cerámica o el del sedimento.
} 
caliza y cerámica triturada. Sólo ha sido posible conocer el diámetro de uno de los vasos, de $11 \mathrm{~cm}(2017 / 5 / \mathrm{E} / 2)$.

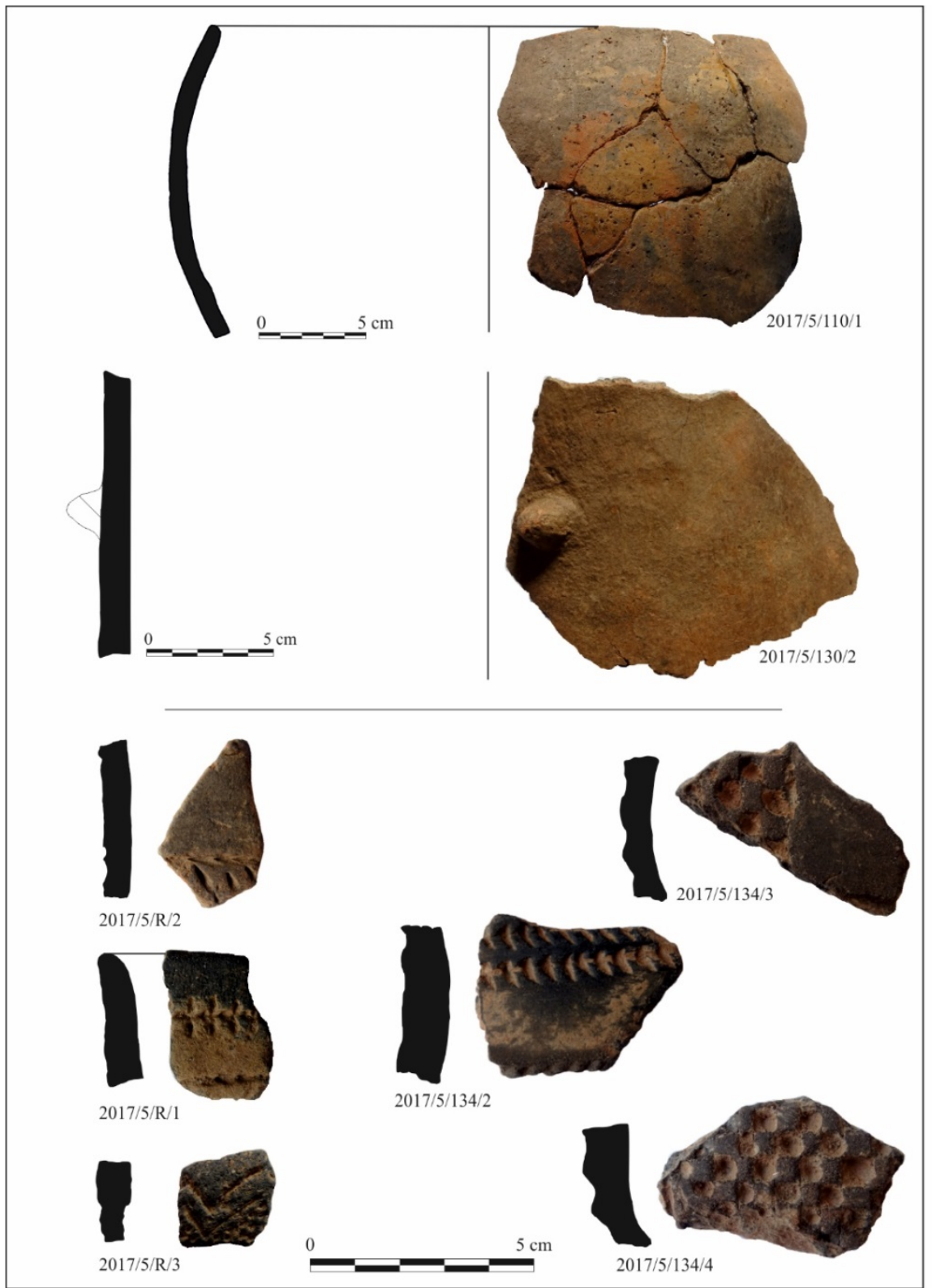

Fig. 7.- Materiales más representativos recuperados en la campaña 2017. 
En los hoyos de poste sólo se pudo identificar, en la EV7, un borde recto de labio redondeado (2017/5/122/1) sin que sus características morfotécnicas difieran de las señaladas. Los otros veintitrés fragmentos de pequeñas dimensiones, amorfos, recuperados en este mismo hoyo parecen haber sido utilizados para ajustar o calzar el elemento hincado.

Entre los entalles negativos con ceniza, sólo se recuperó, en la EV4, una lámina simple de sílex meloso, con bulbo simple y reflejado, que dispone algunos retoques indirectos izquierdos y una posible escotadura, probablemente para ajustar a su enmangue (2017/5/160/1). De los tres restos líticos aparecidos, es el único trabajado y asociado a una estructura.

Tampoco los hogares aportaron un volumen representativo de cultura material. Tan solo en la EV12 se recogieron tres galbos lisos de cerámica realizada a mano, con paredes finas y bruñidas, que no aportan formas tipológicas.

Por tanto, son los rellenos de las cubetas contenedores de vasija los que ofrecieron el mayor número de hallazgos significativos. La EV6 aportó quince fragmentos del cuerpo de una olla (2017/5/110/1) de forma globular de unos 26 cm de diámetro y superficie porosa, posiblemente por haber perdido el alisado final (Fig. 7). En la EV16 se recuperaron veintitrés fragmentos de pequeño tamaño, la mayoría, veinte, informes; otros dos rodados; uno (2017/5/130/1), de un borde vuelto, de labio apuntado, de una vasija de pobre alisado y un diámetro de $18 \mathrm{~cm}$, y, el otro, (2017/5/130/2) una pared de una vasija de gran tamaño con mamelón de forma troncocónica, de superficie rojiza al interior y exterior, bien alisada y cuidada, y un diámetro $31 \mathrm{~cm}$ (Fig. 7). Finalmente, la EV18 contenía seis fragmentos. Dos son informes; otro corresponde al fondo plano (2017/5/134/1) de una vasija de pared gruesa cuyo tamaño se desconoce y cuyo tratamiento exterior parece dispuso de un enlucido oxidante. Los tres últimos ofrecen aspecto similar: cocción reductora y tratamiento cuidado, y distinta decoración (Fig. 7). En uno es incisa, con un motivo de doble línea cosida con incisiones cortas transversales (2017/5/134/2), y los otros con técnica excisa: uno con un motivo de ajedrezado, de metopas, con tres filas en el fragmento recogido (2017/5/134/3), y, el otro, desarrolla un motivo similar del que se reconocen seis filas (2017/5/134/4). Ni uno ni otro motivo se corresponderían con el ritmo y tamaño de los descritos para la cazuela del S12.

\section{CARACTERIZACIÓN E INTERPRETACIÓN DE LOS HALLAZGOS}

Con tan escaso bagaje es complicado caracterizar la atribución cronocultural del enclave y concretar, siquiera, si la ocupación prehistórica corresponde a un único momento o es recurrente. En todo caso, los elementos 
diagnósticos sí parecen suficientemente característicos para confirmar que se trata de un asentamiento atribuible al Grupo Cogotas I, escasamente representado en el extremo oriental de la Submeseta Norte, en contraste con la proliferación de hallazgos en el centro de la cuenca meseteña. También, los datos recogidos permiten reflexionar sobre el desarrollo de estos asentamientos durante dicha etapa en la zona del Alto Duero, al disponer de nuevos elementos con los que valorar los argumentos esgrimidos para sustentar la interpretación sobre su formación y desarrollo en este territorio.

\subsection{Caracterización del asentamiento}

Las evidencias detectadas denotan un típico establecimiento de los denominados "campos de hoyos" que son comunes en el interior peninsular al menos desde el final del Calcolítico y a lo largo de la Edad del Bronce y constituyen una de las manifestaciones más comunes del Grupo Cogotas I (Rodríguez Marcos, 2008: 438-444), etapa a la que se adscriben las cerámicas que se han recuperado en El Hocino. Ciertamente, estas estructuras excavadas en el suelo debieron tener una funcionalidad variada e incluso distinta a lo largo del tiempo, por lo que no permiten una única explicación (Bellido, 1996; Diaz del Río 2009). Junto a ellas y sobre las mismas, en alguna ocasión, se ha documentado la existencia de cabañas de entramados vegetales que se sustentan por postes hincados en el terreno, de los que queda su huella -aunque también se identifican otras cuya delimitación en planta sólo se explicaría por ser complementarias de estructuras más pequeñas, tal vez para proteger los hoyos o, como se ha apuntado, para cortavientos, etc.-, y que junto con los restos de hogares, tanto en el interior como en el exterior de las habitaciones -Los Tomos de Caracena (Jimeno, 1984; Jimeno y Fernández Moreno, 1991), El Balconcillo de Ucero (Rosa, 1995) o El Teso del Cuerno de Forfoleda (Martín Benito y Jiménez, 1988)- confirman una cierta estabilidad de las poblaciones, siempre muy reducidas (Abarquero, 2005: 43-46). La escasa muestra documentada en El Hocino y lo arrasado de las evidencias solo permiten confirmar la existencia de estos elementos comunes en la mayoría de los asentamientos de la época.

Es común la localización de los asentamientos tipo Cogotas I -con independencia de la fase a la que se adscriban- en zona de vega, aunque en el valle medio del Duero se conocen en sitios en altura y en zonas intermedias (Rodríguez Marcos, 2008: 416-446). En la zona del Alto Duero también abundan los enclaves en zonas bajas, junto a las vegas de los ríos -Los Tolmos de Caracena; Santa María de la Riba de Escalote; Fuentelárbol, La Barbolla; Escobosa de Calatañazor o Yuba (Jimeno, 1984: 49-63)- con los que se podría identificar este de El Hocino. Conviven, en todo caso, con los troglodíticos -la Cueva del Asno, la de Covarrubias de Ciria (Ibídem); la del Polvorista de Ucero 
(García-Soto y Moure, 1984: 159) -si bien otras referencias sólo atribuyen una ocupación de este sitio en época campaniforme y del inicio de la Edad del Hierro (Moral y Navazo, 2006-2007: 53 y ss.)-, o los covachos de las laderas de Los Castejones, en los cortados del río Talegones de Calatañazor ${ }^{10}$ (Romero y Delibes, 1978; Jimeno, 1984, fig. 155) o Cueva Maja de Cabrejas del Pinar (Samaniego et alii, 2001)-, siendo más extrañas las localizadas en altura -el ya referido de El Balconcillo de Ucero- lo que refleja un abanico completo de ubicaciones que no permiten discernir un patrón exclusivo para este momento.

Sí es un rasgo repetitivo la localización en muchos de los enclaves de esta época de otros hallazgos que evidencian una reiteración de la ocupación del mismo solar por grupos tanto próximos como remotos, habiendo advertido para los más cercanos una predilección de los de atribución campaniforme y del Bronce Medio, que no del Bronce Antiguo que está menos representado (Blanco, 2011: 129-131) ${ }^{11}$. En el Alto Duero, entre los señalados con anterioridad, las asociaciones con otros grupos cronológicos próximos están peor documentadas aunque existen algunas referencias que las confirmaría, caso del hallazgo de Los Arenales de Rioseco (Fernández Moreno y Jimeno, 1992: 211-229) o la referida de El Polvorista (García Soto y Moure, 1984), por lo que nos atrevemos a decir que, en este territorio, no parece una práctica tan generalizada como en la zona central meseteña, donde es más habitual la existencia de cortes tangenciales de muchas de estas estructuras por otras más recientes, confirmando la reutilización consciente de los mismos espacios, como denuncia la existencia de zonas inmediatas, similares y limpias que existen en los alrededores (Abarquero, 2005: 44-46).

Por el contrario, en el Alto Duero no es extraño el hallazgo de cerámicas de adscripción tardorromana y otras medieval/modernas junto a los tipos cerámicos que tratamos, evidenciando la ocupación de los mismos espacios por gentes de distinta época. Además del caso de El Hocino, se pueden señalar muchos de los yacimientos ya citados: el propio de Los Tolmos, el de Santa María; la Cueva del Asno o Cueva Maja.

\footnotetext{
${ }^{10}$ También se identificaron diversas cerámicas con decoración, incisa, excisa y de boquique en la ladera contraria, en la base de la muralla que rodea la Villa, durante el Control arqueológico de las obras de consolidación, urgencia y seguridad en distintos puntos de la Muralla de Calatañazor, 2013; Informe inédito, depositado en el Servicio Territorial de Cultura de Soria.

${ }^{11} \mathrm{Al}$ respecto hay que señalar que la utilización de datos procedentes de la Carta Arqueológica de Castilla y León, dada la diferencia de criterios utilizados para la determinación cronocultural de los hallazgos, puede conjeturar asociaciones no contrastadas -no debe olvidarse que las adscripciones se sustentan en la identificación de tipos formales/decorativos sobre hallazgos superficiales, por equipos distintos y en años diferentes-. Para esta problemática en el territorio del Alto Duero en J. J. Fernández Moreno: El Bronce Antiguo en el Oriente de la Submeseta Norte, Tesis Doctoral; 2011; Cap. 3. El registro Arqueológico,..., accesible en https://eprints.ucm.es/22975/1/T32979.pdf.
} 
Las asociaciones recurrentes de grupos próximos reflejarían una continuidad en la que se han destacado determinados valores socioeconómicos e ideológicos (Díaz del Rio, 2001; y Blanco, 2011: 130 y ss.), cuestión que parece más difícil de aceptar para las asociaciones con grupos lejanos y evidentemente distintos. Por ello, a nuestro entender, para explicar estas coincidencias debe valorarse la asociación de estos enclaves a su localización y características topográficas que, en el caso de las cuevas estarían determinadas por su utilización como refugio natural -de protección si consideramos que estos enclaves constituyen espacios de habitación, lo que no hay que dar por exclusivo- y en el caso de los lugares en zonas bajas de vega por aprovechamiento y control de recursos naturales -interés por el control, cultivo y aprovechamiento de las tierras más fértiles-.

En el caso de El Hocino, por las evidencias documentadas, nos encontramos ante los restos de un asentamiento de la plenitud de la Edad del Bronce probablemente abandonado al destruirse por algún episodio de arroyada e inundación del río Duero. Y algo similar debió de ocurrir siglos después con otro asentamiento de época romana del que apenas quedan vestigios materiales. Y aún, en una tercera ocasión, con un pequeño poblado medieval. Al menos, en los dos momentos más antiguos, se constata la amortización de las estructuras identificadas por una potente capa de limos de sedimentación, aportados por una potente arroyada, lo que sin duda explica el fin de los asentamientos.

Llama la atención el reiterado empeño de distintas gentes por ocupar unos terrenos de inundación. El control o la fertilidad de los suelos no deben de ser las únicas explicaciones de tal insistencia por cuanto éstos podrían ser igualmente accesibles y vigilados si se hubiera instalado el poblado en la terraza superior que, aunque algo alejado, posibilitaría un fácil acceso y un mejor control visual de la zona. Alguna otra causa debió de ser lo suficientemente importante y/o condicionante para contrarrestar los riesgos que evidenciaba el lugar y que finalmente supusieron su destrucción. Al respecto, queremos recordar, la asociación de las formaciones de travertinos con fuentes de aguas de gran calidad que, seguramente, aportaran un interesante plus para determinar la ubicación de los asentamientos, tanto por su aprovechamiento directo, por la posibilidad de irrigación de determinados cultivos o, incluso, la existencia de zonas húmedas durante todo el año.

\subsection{Encuadre de los hallazgos}

Considerando las características de las estructuras identificadas, resulta obligado centrarnos en el análisis de los materiales para aproximarnos a su cronología. El conjunto de cerámicas, aunque bastante uniforme, también es muy limitado. Destaca en lo decorativo la convivencia de las tres técnicas - 
salvando la impresión- más representativa de Cogotas I: la incisión, el boquique y la excisión; incluso, como se ha visto, combinadas en la excepcional cazuela que, sin duda, marca la diferencia de los hallazgos.

En las últimas décadas del siglo pasado se redefinió la cronología de este grupo meseteño de la Edad del Bronce y se discutió su etnogénesis a partir, sobre todo, de la presencia/ausencia de la excisión entre las técnicas decorativas. Ello dio pie, simplificando, a dos corrientes interpretativas: una que planteaba un desarrollo evolutivo a partir de los campaniformes locales con los que se había propugnando una continuidad evolutiva desde los elementos incisos y pseudoexcisos (Fernández-Posse, 1981; Jimeno, 1984; Fernández Moreno y Jimeno, 1992; Fabián, 2012: 341- 344; Fernández Moreno, 2013: 228-223), sobre todo a partir de que la técnica excisa rompiera las ataduras europeas y se aceptaba su poligénesis (Molina y Arteaga, 1976), al igual que la del boquique se consideraba de amplia tradición local (Fernández-Posse, 1982); y otra que, admitiendo la evolución local en lo relacionado con la incisión e incluso con el boquique, requería aportaciones externas para justificar el desarrollo de la excisión en la última de las tres etapas en las que se articulaba el desarrollo de Cogotas I (Fernández-Posse, 1986/1987). Pese a la carencia de referencias estratigráficas que respalden la secuencia e incluso pese a su cuestionamiento por las evidencias cronológicas (Fernández-Posse, 1998: 95100), se vino considerando que en la fase inicial, formativa, dominarían las decoraciones incisas, incorporándose el boquique y minoritariamente la excisa en la fase plena o clásica, mientras que en la fase final, manteniéndose la incisión y el boquique, aumentaría la excisión en detrimento del último. Por tanto, la excisión surgiría en un momento avanzado y su máximo desarrollo se vinculaba a formas cerámicas nuevas, quebradas, que denotaban una ruptura clara con las culturas anteriores (Abarquero, 2005; Rodríguez Marcos, 2008).

Recientemente, a partir de la revisión de las inhumaciones y un nuevo repertorio de dataciones, se ha concretado una secuencia de dos fases: Protocogotas -ente 1800 y 1450 cal AC-y de Plenitud o propiamente Cogotas I -de 1450 a 1150 cal AC- Abarquero et alii, 2013: 316-317 y fig. 1); concluyendo que los porcentajes de representación de las distintas técnicas decorativas, que sirvieron de justificación en su día para la anterior división, debieran explicarse por causas distintas al marco temporal (Esparza et alii, 2012: 269 y 313), retomando la de la diferenciación regional de grupos (Fernández-Posse, 1998: 96) que ya había sido recuperada para los temas incisos (Rodríguez Marcos, 2008: 321-327).

Del conjunto de El Hocino, tipológicamente la pieza más completa corresponde a perfiles carenados medios, comunes y propios de la etapa intermedia de la Edad del Bronce que encuentran antecedentes en la fase inicial. Por sus dimensiones, se incluiría entre las denominadas cazuelas, con un índice 
de proporcionalidad anchura/altura (IP) de 1,92 en relación al borde y 2,12 si se considera a la máxima anchura de la carena. Para los campaniformes típicos de valle del Duero (Martín Valls y Delibes, 1989) el IP oscila entre 2,5 y 2,10 en el caso de las cazuelas -en este caso la anchura máxima del borde y la carena suelen ser coincidentes o próximas-, si bien éstas muestran el borde claramente exvasado, al contrario que la de El Hocino.

Esa misma diferencia parece una constante al comparar la silueta con las cerámicas del II milenio AC. En el Alto Duero, en el cercano yacimiento de El Parpantique, la forma más parecida sería la B2a (Fernández Moreno, 2013: 136, Fig. 39) tanto por la altura de la carena como el cuerpo inferior de paredes rectas, si bien el cuerpo superior se diferencia con un perfil ligeramente cóncavo de borde saliente. Aun así, se trata de una variante poco representada en esta fase en la que abundan las paredes inferiores convexas. Más similitudes pueden encontrarse entre las formas reconocidas en Los Tolmos, atribuido ya a la fase Protocogotas. En este conjunto siguen predominando las paredes convexas o globulares en el cuerpo inferior de estas formas, si bien se conocen algunos cuerpos rectos. En todo caso, sigue la generalidad del borde saliente (Jimeno y Fernández Moreno, 1991: 23, Fig. 13-C y 14).

Para la etapa avanzada, uno de los conjuntos que cuentan con un estudio cerámico más detallado es el de La Requejada de San Román de Hornija en el extremo occidental meseteño. Entre las cerámicas decoradas destacan las de forma troncocónica, por ejemplo, la A5 (Delibes et al., 1990: 73, Fig. 20) que se asemeja por el perfil sinuoso, ligeramente entrante del cuerpo superior, aun cuando el borde sigue siendo saliente. Este tipo presenta también el cuerpo inferior plano, pero por la altura de la carena y las proporciones difiere claramente, hasta el punto de incluirse en el conjunto de los vasos.

El ejemplar que presentamos se situaría en una posición intermedia entre los diferentes modelos, si bien al ser un únicum no posibilita conocer tendencia, que es las que define los conjuntos estudiados. Por ello resulta interesante valorar la evolución de estas formas en la zona de la Ribera del Duero, en la provincia de Valladolid, en un estudio secuencial en cuatro fases: desde el Calcolítico Final al Bronce Final (Rodríguez Marcos: 2008). En la fase más antigua, las formas carenadas son escasas, tan sólo se identifican algunos ejemplares -de carena alta- en el yacimiento de Pico Castro (Ibídem: 270, Fig. 189, 8). En la etapa siguiente, que denomina Bronce Antiguo-Pleno, se distinguen distintos perfiles quebrados, como el tipo 11 (Ibídem: Fig. 190) de cuerpo ligeramente convexo, carena alta, cuello recto y borde saliente que recuerda a las comentadas de Los Tolmos, y aunque se asemeja a la de Fuentetovar, difiere en la altura de la carena y el desarrollo del cuerpo al que hemos de suponer, además, un fondo umbilical que remataría el casquete inferior, y ello pese a que el denominado índice de alargamiento -proporción de 
anchura dividido por altura- de 0,51 seria equiparable a IP de aquella. Como está bien contrastado, será en la fase siguiente, allí denominada del Bronce Medio cuando las cerámicas carenadas tengan una mayor presencia. Se identifican hasta cinco formas distintas, además de algunas variantes. Aunque las más abundantes y representativas corresponderían a las carenas medias Formas 12 a 14-, la más próxima a la que nos ocupa sería la 15B de aquella tabla (Ibídem: 305-312, Fig. 193). Este ejemplar ofrece el cuerpo inferior de paredes rectas, si bien la carena se situaría en el tercio superior -no está completa- y el cuello está más marcado que en los casos anteriores. También, aunque ofrece dudas su clasificación para el autor del estudio, la numerada como 14, lisa (Ibídem: 193), dibuja un perfil próximo a la de El Hocino, si bien la altura de la carena y la proporción de la pieza ofrecen argumentos para considerarla un tipo distinto. En la última etapa analizada en ese estudio, la del Bronce Tardío/Final, los vasos carenados más habituales son los troncocónicos. En el cuerpo inferior encontramos semejanzas indudables, mientras que la disposición alta de la carena obliga al desarrollo de un corto cuerpo superior saliente que contrasta incluso con los perfiles más próximos (Ibídem: Fig. 200, 14B). Hay que resaltar, en todo caso, que los tipos de esta última etapa en la zona de La Ribera, no cuentan, pese a la existencia de claras semejanzas, con los más característicos de la etapa Plena de Cogotas I: ni los esbeltos vasos troncocónicos, ni rodetes, copas o las jarras polilobuladas que le caracterizan (Blanco, 2014: 307-308), como en el citado caso de La Requejada o en Carpio Bernardo (Abarquero, 2005, Fig. 5 y 6).

El resto del material recuperado en el asentamiento de Fuentetovar tiene paralelos más claros, si bien son tipos más comunes que posibilitan una menor precisión cronológica. El cuenco de borde entrante y paredes verticales -tipo cubilete- tiene un largo recorrido, generalizando su presencia en los conjuntos atribuidos a la fase Protocogotas: forma A1 de Los Tolmos (Jimeno y Fernández Moreno, 1991, Fig. 12) o tipo 6A del Bronce Medio en la Ribera (Rodríguez Marcos, 2008, Fig. 192). La ollita de mediano tamaño, de ligero perfil en "S" poco marcado, casi bicónico, se identifica en los mismos conjuntos: como E2 en Los Tolmos y 10A en La Ribera, estando ausentes en las etapas anteriores en ambas zonas.

Desde el punto de vista decorativo no existe duda sobre la adscripción a Cogotas I de la composición, incluso, atendiendo a la combinación de las tres técnicas identificadas, su atribución a la fase Clásica o Plena. A pesar de ello, no hay referencias estratigráficas ni cronológicas que obliguen a considerarla exclusiva de ese periodo.

Si atendemos a la división del Grupo en las dos etapas referidas Protocogotas y Cogotas I-, entre los yacimientos adscritos a la primera identificamos piezas que combinen en la misma decoración estas técnicas en 
Los Tolmos, entre los restos recuperados en superficie (Jimeno, 1984, núm. 1551 y 1553). En ese poblado, como es sobradamente conocido, no son extraños los boquiques formando bandas, guirnaldas, etc., ni los motivos excisos de triángulos, bandas, zigzags, etc., tanto localizados en la parte exterior como en el interior de los vasos.

En el esquema de desarrollo tripartito de Cogotas I, se asocia la vinculación de excisión y boquique a las fases más avanzadas (Abarquero, 2005: 31). Por ello se cuestionó (Rodríguez Marcos, 2008: 364-365) si las cerámicas con boquique y excisión de Los Tolmos corresponderían a la ocupación adscrita a la fase formativa o bien constituirían evidencia de un asentamiento posterior, ya de la fase intermedia de la antigua clasificación. Pensamos (Fernández Moreno, 2013: 177) que hay argumentos estratigráficos que confirmarían la presencia de ambas técnicas junto a la incisión desde el principio de la ocupación, si es que hubiera habido otras. Aun siendo un establecimiento recurrente y estacional, primavera-verano, no parece que tuviera una dilatada existencia a tenor de la uniformidad de los materiales y la ausencia de superposiciones de las estructuras. En el área de las inhumaciones del Sector B -con fechas que la adscriben a la fase Protocogotas- se recuperaron dos excisas estratificadas: una, sobre vaso de carena alta, con motivos triangulares alternos y otra, sobre un vaso de perfil en "S", con motivos rectangulares al exterior y triangulares en el interior del borde (Jimeno, 1984: 97).

En la zona inmediata de la Ribera del Duero tan sólo se referencia un ejemplar que combina la excisión y el boquique en el Gurugú (Bocos de Duero). Es este un yacimiento en altura que se atribuye -por la presencia de decoraciones de boquique, recuperadas mayoritariamente fuera de contexto- a la fase Plena de Cogotas I (Rodríguez Marcos, 2008: 187-213 y 370; Fig. 152), si bien carece de datación radiométrica.

Otro ejemplo parecido, lo constituyen diversas escudillas del yacimiento burgalés de Las Veguillas, en la propia ciudad. Formalmente los perfiles corresponden a la forma B -entre las decoradas- de la tipología de San Román de Hornija. En este caso, la decoración desarrolla motivos excisos triangulares contrapuestos que dibujan un zigzag en resalte o lo que pudieran ser dameros incluidos en esquemas metopados, delimitados tanto por incisión como por boquique y que se enmarcan por líneas cosidas. El asentamiento se conoce por un centenar de estructuras negativas con material muy uniforme, según sus excavadores, atribuible a la fase Protocogotas a excepción de las estructuras que contiene el material descrito que se atribuye a la fase de plenitud (Alonso y Jiménez, 2012: 362-363; Lám. II). No obstante, por la falta de otra argumentación, hay que considerar que la adscripción cronocultural se determina, precisamente, por las técnicas decorativas, toda vez que las formas 
también se identifican en el momento formativo y no se significan otros rasgos exclusivos de la fase Cogotas I.

Siguiendo la secuencia analizada para las formas, en el conjunto de San Román de Hornija se confirman nuevos paralelos (Delibes et alii, 1990, Fig. 9, 2; 10, 8; Fig. 12, 2; Fig., 13, Fig. 14, 2). Se ha señalado (Ibídem: 78), y también lo compartimos, que la diversidad de diseños es una característica en las producciones de Cogotas I, por lo que intentar identificar esquemas idénticos es tarea ardua a pesar de la repetición de muchos de los motivos. En este caso la temática y asociación de técnicas serían similares, si bien, las formas que desarrollan las cerámicas de este yacimiento -vasos y escudillas- son propias de la fase más evolucionada del complejo, claramente diferenciada que las que acabamos de indicar. $\mathrm{Y}$ dado que se ha considerado un yacimiento de corta existencia, por la homogeneidad de los materiales y su distribución (Ibídem: 68 y 69), la reciente datación de la conocida inhumación en fosa y su combinación con la de un hogar -entre 1368 y 1211 cal AC, con distinto rango de probabilidad- ratifica su adscripción a la fase clásica, sin que ello condicione la presencia de los tipos antedichos en épocas anteriores.

Los vasos de Pico Castro de Dueñas también se adscriben a esa misma fase. Se trata de tres cerámicas muy semejantes, decoradas con técnicas mixtas, al menos los vasos 2 y 3 desarrollan una ancha banda divida en metopas con motivos conseguidos mediante excisión, boquique e incisión. Además, bajo el borde, los tres cuentan con una fina banda de dientes de lobo pseudoexcisa en el caso del vaso 1, excisa en el número 2 e incisa en el número 3 (Blanco, 2014: 318; Fig. 8). Sin duda, las similitudes con la cazuela de El Hocino son evidentes. Especialmente en la distribución de la decoración en dos zonas, una estrecha bajo el borde y otra más ancha sobre la carena. El motivo de la superior del vaso 1 recuerda a la típica de los vasos Ciempozuelos (Martín Valls y Delibes, 1989: Fig. 5, 17 y 19; Garrido-Pena, 2000: Figs. 46 a 48) y a la propia del El Hocino. La inferior y principal, por el tamaño, coincide con ésta en la división metopada, si bien el los vasos de Dueñas alternan zonas lisas con las decoradas y en el ejemplar soriano la decoración ocupa todo el contorno. Formalmente, encontramos algunas diferencias. Las palentinas se han adscrito al tipo 9C del Bronce Tardío-Final de Rodríguez Marcos (2008: 344; Fig. 199) que corresponde, como ya se ha referido, a una "vasija de cuerpo eliptico con paredes marcadamente convexas y borde ligeramente vuelto" y que dicho autor relaciona con el tipo A6 de La Requejada, ya comentado, que es el único de los vasos troncocónicos que no diferencia carena. Este hecho y el índice de alargamiento -0,37- equivalente a un IP de 1,4, son argumentos para considerar que formalmente estamos ante tipos distintos. El hoyo donde se recogieron estos vasos, junto a otro material de almacenaje, tampoco cuenta con datación radiocarbónica, si bien los paralelos con San Román de Hornija llevan a situar su deposición en una fecha similar. 
Otros ejemplos que combinan estas mismas técnicas son los recipientes salmantinos de Carpio Bernando. Uno de ellos (Abarquero, 2005: Fig. 5, 6) presenta metopas alternas de ajedrezados y bandas rectangulares que ocupan la parte inferior del vaso, mientras que el cuerpo superior se decora con doble línea paralela de boquique. Genéricamente se atribuyen estos conjuntos, junto a los de Sanchorreja, El Berrueco, Areneros del Manzanares o Santo Domingo de Silos, a una fase Evolucionada de Cogotas I y se plantea su prolongación por la similitud de algunos de los perfiles a las formas hallstátticas y la distribución de los esquemas decorativos (Martín Valls y Delibes, 1976; Delibes et alii, 1990: 82). Por ello se ha visto una posible relación de continuidad del mundo Cogotas I en algunas cerámicas del Hierro I en las que se describen esquemas decorativos a base de motivos excisos delimitados, igualmente, mediante líneas de boquique (Fernández Moreno, 1986; Álvarez y Pérez, 1987), relaciones que debieron ser recíprocas como demuestran las características de algunas cerámicas del conjunto de Los Quintanares de Escobosa de Calatañazor (Jimeno y Fernández Moreno, 1985), pero esto nos llevaría a otra cuestión que nos aleja del debate sobre el origen de estas técnicas y la de su asociación en la Edad del Bronce.

Pese a las similitudes de los motivos e incluso de la combinación de técnicas para su ejecución que se señalan entre la cazuela de Fuentetovar y las cerámicas de la fase avanzada que se han descrito, es cierto que se advierten claras diferencias en cuanto a la forma de los soportes.

Si atendemos a la distribución de la decoración -bajo el borde y en el tercio superior, sobre la carena- los mejores paralelos se identifican en piezas atribuidas a Cogotas I sin dejar de reconocer ejemplos en la fase Protocogotas. Ciertamente, como en los vasos Ciempozuelos, los esquemas distributivos se repiten, constatando, además de la utilización de los espacios señalados, la distribución radial desde la base hacia la parte superior del vaso o la utilización interior del borde.

En suma, no hay argumentos contextuales que permitan atribuir la cazuela de Fuentetovar a un momento distinto de Cogotas I. Sus características morfotipológicas y decorativas permiten argumentar su adscripción a cualquiera de las dos fases en las que se agrupan las distintas dataciones de los hallazgos adscritos a dicho grupo arqueológico. Ahora bien, paralelamente, se viene insistiendo en identificar elementos exógenos que hubieren ¿impulsado? el desarrollo de la técnica excisa, cuyas evidencias más antiguas se localizan en el sector oriental de la Submeseta Norte -Los Tomos de Caracena-, en concreto a partir de la imitación o emulación de determinados vasos cerámicos de tipo Duffaits identificados en cuevas del reborde montañoso meseteño (Blanco, 2015: 44-47). 
El primer caso, una taza, se identificó en la Cueva del Asno, en el frente A del Sector B en la campaña de 1976, en concreto en el nivel "r" que se sobreponía a otro inferior denominado "a" que aportó una fecha de 14C de $3380 \pm 50$ a. C. (Eiroa, 1980: 19-20 y 44-45; y fig.: 8 y 12). Posteriormente, se explicó la presencia de este singular vaso como un intercambio puntual, posible ajuar de dote, pero del que no se conocen en este territorio ni imitaciones ni evoluciones (Delibes et alii, 2000). Cinco fragmentos de otro ejemplar, probablemente pertenecientes a una pieza similar a la anterior, fueron identificados en la Cueva del Mirador, en la burgalesa Sierra de Atapuerca, localizados uno en el nivel 4, tres en el nivel 3 superior, y otro en el definido como nivel 2 que contiene materiales en posición secundaria (Moral et alii, 2003-04: 59-60, Fig. 4). Cronológicamente el nivel 4 se desarrolla entre $3380 \pm 40$ a. C., de la base, al $3040 \pm 40$ a. C., en la que se fecha el techo del mismo (Ibídem: 11-12). Se da la interesante circunstancia que en el nivel 3 se identifica un hacha de rebordes (Ibídem, 121-122), asociación habitual también entre los hallazgos del Grupo Duffaits (Gomez, 1995: 47-52). Menor precisión aporta la identificación a este mismo conjunto de otra cerámica del yacimiento de Castilviejo de Yuba, por cuanto se desconoce su contexto, en un enclave en el que coexisten materiales de diversas épocas (Ruíz Zapatero, 1984: 177; Delibes et alii, 2000: 114). Un cuarto caso se ha querido ver entre las piezas de Cueva Maja (Blanco, 2015: 45) ${ }^{12}$, aun cuando los responsables de la excavación no apreciaron presencia de excisión alguna ente los motivos decorativos (Samaniego et alii, 2001).

La adscripción de los vasos de la Cueva del Asno y los de la del Mirador al tipo de tazas Duffaits no parece cuestionable, si bien presuponer que pudo haber sido un modelo a partir del cual se desarrollara la técnica excisa de Cogotas I es algo que no parece tan evidente. En primer lugar, la cronología del grupo Duffaits se sitúa, grosso modo, en la segunda mitad del segundo milenio en fechas calibradas, pese al amplio margen de error que ofrecían seis de las siete dataciones disponibles para su definición (Gomez, 1995: 73-74). Las fechas calibradas de los hallazgos meseteños (1780-1520 cal AC para el nivel inferior del hallazgo de la Cueva del Asno y 1420-1130 cal AC para el nivel 4 de la Cueva del Mirador) ofrecen márgenes (Fernández Moreno, 2013: Fig. 17) que

\footnotetext{
${ }^{12}$ La atribución de cerámicas de Cueva Maja al tipo Duffaits se realiza sin mayor concreción. La referencia al texto de la memoria de Cueva Maja (pág. 58) no es aclaratoria por cuanto en la página referida se relacionan los criterios de adscripción tipológico funcional de las cerámicas a partir de la media del Índice del Tamaño, por lo que suponemos debe tratarse de un error. En cuanto al apartado gráfico, la referencia a la citada Memoria indica una figura (la 91) en la que se reproducen fragmentos correspondientes a diversos vasos. En ningún caso la técnica reconocida en ellos es la excisión o estampación que resultan las más genuinas del grupo francés, toda vez que las incisas e impresas son habituales en diversos grupos de cronología inmediatamente anterior, entre ellos los meseteños.
} 
posibilitarían aceptar su llegada en una fase muy inicial de aquel Grupo, en el que se constatan, eso sí, estos mismos tipos y decoraciones (Gomez, 1995: 7882). En el supuesto del caso de Cueva Maja, la atribución de la pieza a dicho grupo conllevaría encontrar un paralelo antes de que se constatara la existencia del modelo, toda vez que la ocupación de esta cavidad se confirma en el lapso de 2220 a 1930 cal AC (Samaniego et alii, 2001: 91-93).

Entre las razones esgrimidas para desestimar la evolución de la excisión a partir de la técnica pseudoexcisa es su consideración como dos técnicas distintas que producen resultados diferentes (Rodríguez Marcos, 2008: 371). Paralelamente, también defendió que la decoración de la taza de la Cueva del Asno no correspondía a los modelos excisos del Hiero I, sino que se asimilaba a los pseudoexcisos atribuible al Bronce Medio (Jimeno, 1985: 102). De nuevo, se propugna su realización con la técnica excisa (Delibes et alii, 2000: 100). Es clara la diferenciación de una técnica y otra, y sobre todo es evidente que producen efectos distintos, bien sea por los gestos técnicos bien por la intencionalidad del artesano para conseguir una superficie rugosa o una superficie alisada (Fig. 8). Al respecto, sería oportuno considerar la denominación de "pseudoexcisa" a la técnica que se aplica a los vasos campaniformes incisos, y por extensión a la similar de época posterior, por cuando probablemente fuera más preciso definirla como de impresión. En cuanto al caso de la taza de la Cueva del Asno, la cuestión no sería muy diferente. Tal vez, por el tamaño y profundidad de triangulo se haya retirado pasta mediante cortes laterales, pero es indudable que el tratamiento final que queda es el de la impresión, cuidadosa, de un aplique triangular del tamaño del motivo. En todo caso, una y otra, son absolutamente diferentes de las técnicas y, sobre todo, del resultado que se advierte en los vasos de Los Tolmos o El Hocino. En ambos, la extracción se ha efectuado con diferentes y sucesivos gestos que producen huellas de desgaje de la pasta y una intencionada rugosidad de la zona de extracción. Por todo ello, tan posible como imposible pudiera considerarse la evolución de las técnicas de los dos primeros ejemplos hacia los segundos. Lo único claro, es que el resultado es claramente diferente entre unos y otros. 


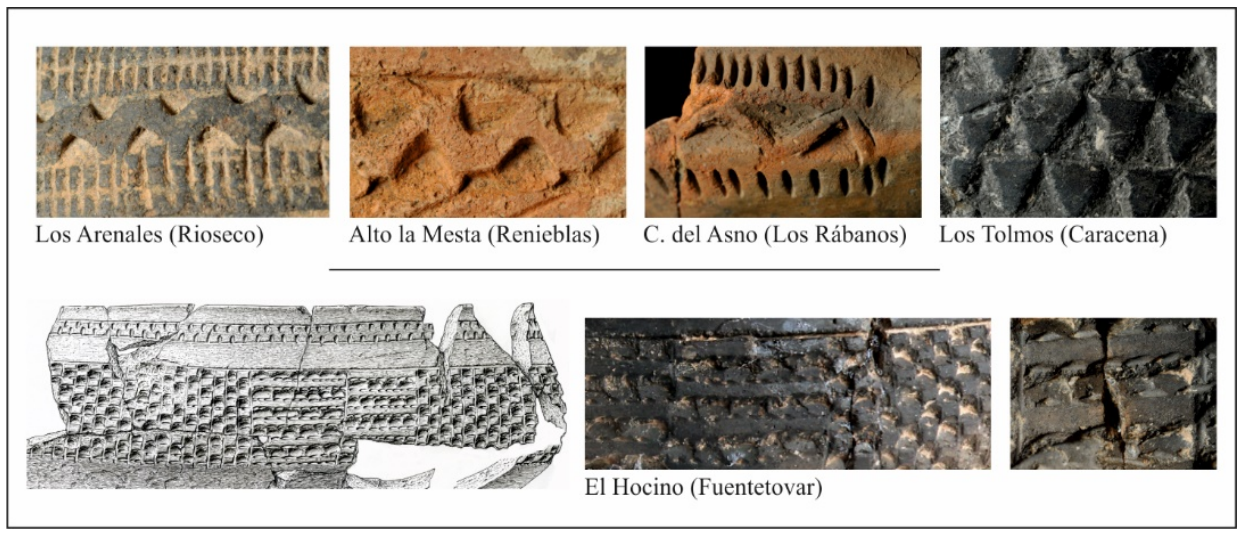

Fig. 8.- Detalle de las improntas de los distintos motivos decorativos: "pseudoexcisos", Los Arenales de Rioseco y Alto de la Mesta de Renieblas; "tipo Duffaits”, Cueva del Asno; “excisos”, Los Tomos de Caracena; detalle de la cerámica de El Hocino de Fuentetovar. (Fotografías de A. Plaza, Museo Numantino, Junta de Castilla y León).

El propio Gomez (1995: 64) advierte, para las cerámicas Duffaits, lo legítimo de tratar conjuntamente las técnicas excisa e impresa utilizadas para la configuración de los motivos más comunes, que quedarían preparados para recibir otros materiales -pasta- para conseguir combinaciones de color. Advierte, asimismo, que, ambas, pueden aparecer mezcladas en el mismo recipiente, y lo más importante, que producen el mismo efecto, llegándose, incluso, a equivocarlas en las referencias bibliográficas.

Efectivamente, tanto las cerámicas decoradas campaniformes como las de Cogotas I y Duffaits se han denominado de incrustación, y a tenor de diversos análisis se puede asegurar que, en determinados casos -no en la cazuela de Fuentetovar- ha sido posible identificar la aplicación de pasta de distinto color, mayoritariamente blanca, aunque también se conocen en las cerámicas cogotianas ejemplos de color rojo e incluso amarillento. La diferencia del material identificado en algunos análisis: calcita para el campaniforme (Martin Valls y Delibes, 1989: 41), y huesos triturados para vasos de Cogotas I, se utiliza como argumento para determinar el hiato temporal entre unas cerámicas y otras, lo que anularía la hipótesis evolutiva a favor de la hipótesis de emulación (Blanco, 2011: 139). Por ahora estas diferencias puntuales pueden explicarse por distintas causas: disposición de materia prima, procesos de mejora técnica, etc., indistintamente de la influencia de las referencias tiempo y espacio, que tampoco parecen influir en lo concerniente a la configuración de los diseños o esquemas decorativos.

Volviendo a la cuestión del origen de la utilización de la técnica excisa entre las decoraciones cerámicas de Cogotas I, hay que recordar que cerámica 
excisa no sólo está presente junto a boquique e incisión en yacimientos considerados de la fase Protocogotas, como Los Tomos (Jimeno, 1984, Jimeno y Fernández Moreno, 1991), sino también, en fases anteriores, como en el poblado del Bronce Antiguo de El Parpantique, donde se identifica un fragmento con boquique y dos con excisión (Fernández Moreno, 2013: 174 y ss.), o en La Muela de Sabucor (Picazo, 1993: 23) ya al otro lado del Sistema Ibérico, en el denominado Bronce Turolense, que ofrece evidentes paralelos, también cronológicos, con el Grupo Parpantique (Fernández Moreno: 2013: 177-178). De tal forma, se confirmaría que estas técnicas están presentes desde los primeros compases de formación del Grupo Cogotas I, tal como se había apuntado (Fernández-Posse, 1979 y 1981; Delibes y Fernández Miranda, 1990: 26), concretándose su gestación en la etapa final del Calcolítico/Bronce Antiguo (Delibes et alii, 2000: 109).

Tanto en El Parpantique como en La Muela, la singularidad de estas piezas -y alguna otra con incisión e impresiones de puntos-, pudiera generar dudas sobre la sincronía con el resto de los materiales, incluso suponer que correspondieran a indicadores de una ocupación ligeramente posterior, asentamientos recurrentes de un mismo espacio por grupos distintos. En el caso del yacimiento soriano, se descartó tal posibilidad por la localización topográfica de los hallazgos. Igual ocurrió con los fragmentos campaniformes localizados en el poblado contemporáneo de Los Torojones (Fernández Moreno, 2013: 173). Estas piezas, junto a la incisas, representan apenas el 2,9 y el 1,9 \% de los materiales decorados -incluidas las aplicaciones plásticas- que, a su vez, apenas constituyen el 19,3 y el 17,7\% del conjunto de las cerámicas que caracterizan ambos poblados. Un panorama que no es único en el oriente de la Submeseta Norte. En sendos asentamientos, topográfica y cronológicamente asimilables a los anteriores, se constatan hallazgos similares como el vaso inciso de Pico Romero en Santa Cruz de la Salceda (Rodríguez Marcos y Palomino, 1997: 587) o los fragmentos campaniformes de Pico Castro en Quintanilla de Arriba, en el que su excavador advierte una única ocupación en el tránsito del Calcolítico a la Edad del Bronce (Rodríguez Marcos, 2008: 131-149).

Una constante, por tanto, que puede indicar la existencia de contactos de diversos grupos con y sin campaniforme que, de una u otra manera, convivieron temporalmente en el oriente meseteño, manteniendo una cultura material diferente. En estos contactos, y en la evolución de los grupos, puede rastrearse la génesis formativa de Cogotas I. Formalmente, cuentan conjuntamente con todos los elementos que luego caracterizaran al Grupo: tanto la diversidad en la ubicación de los poblados, las estructuras de habitación perecederas, las estructuras negativas polifuncionales, la práctica de inhumación en fosas, etc. En cuanto a la cerámica, no parece cuestionarse la influencia de la incisión e impresión de larga tradición desde los grupos calcolíticos y del campaniforme Ciempozuelos en las decoraciones incisas de Cogotas I (Jimeno y Fernández 
Moreno, 1984: 104-108; Fig. 65), e incluso la evolución de su tipología cerámica a partir de tipos anteriores (Ibídem: Fig. 62 y 63); si bien es cierto que se admite desde una doble perspectiva: como una simbiosis evolutiva de motivos decorativos y formas cerámicas de Ciempozuelos y Parpantique que pudieron convivir (Fernández Moreno, 2013: 149-165) o bien como un contacto/emulación lineal de elementos aglutinados en determinados grupos del Bronce Antiguo entre los que se identifican los atribuidos a la fase Protocogotas (Rodríguez Marcos, 2012: 147-164). Tampoco, parece cuestionarse la posible asimilación de la técnica de boquique de amplio recorrido en las etapas antiguas (Fernández-Posse, 1982), más cuando está perfectamente documentada su combinación en cerámicas Ciempozuelos (Blanco, 2015: 42-43; Fig. 2).

Es claro que el hallazgo que se presenta en este trabajo no añade nuevos argumentos para avanzar en esta dicotomía que, a nuestro entender, sigue pendiente de resolución ante la falta de evidencias estratigráficas irrefutables. La mayoría de las referencias en las que se sustenta la aparición de dichas técnicas provienen de hallazgos efectuados en las décadas en las que se redefinió Cogotas I (Delibes, 1978; Fernández-Posse, 1979 y 1981; Delibes y Fernández Manzano, 1981; Jimeno, 1984; Delibes y Fernández Miranda, 1990; Jimeno y Fernández Moreno, 1991) sin que los nuevos y recientes hallazgos, pese a su reconocido interés y concreción en la datación, añadan datos concluyentes a la secuencia. Tan sólo el análisis conjunto de las evidencias funerarias ha posibilitado, como se ha señalado, aclarar la posible evolución del Grupo (Esparza et alii, 2012; Abarquero et al. 2013). Por ello, sería conveniente, en nuestra opinión, derivar el protagonismo de estas cerámicas no tanto en la técnica aplicada para su decoración, como el repertorio cerámico al que se asocia y con los que convive en cada enclave; a la composición de los motivos que configuran los esquemas decorativos y a la localización de las piezas en su contexto. Todo ello sin olvidar, ciertamente, el tipo de asentamiento, la ubicación de las cerámicas y su relación espacial y funcional.

Ya se ha señalado el uso de determinadas cerámicas Cogotas I a actividades de carácter ritual (Blanco 2011 y 2014) que, salvando las distancias, no son ajenas a las del uso de los vasos Ciempozuelos como ajuar en las tumbas de aquel momento. Así mismo, se ha indicado la agrupación espacial de las cerámicas Cogotas I en determinados espacios de los yacimientos (Blanco, 2011: 132), lo que hace suponer una organización en el almacenaje o desecho de los vasos decorados o, al menos, el tratamiento singularizado de algunas de las cerámicas profusamente decoradas. Los hallazgos de El Hocino responderían a los mismos presupuestos, en cuanto las cerámicas decoradas aparecen en depósitos arqueológicos, se agrupan en una (EV18) de las estructuras identificadas. Por lo que respecta a la cazuela, se localizó in situ, y los perfiles de los contornos de los distintos fragmentos muestran una ruptura limpia que pudo deberse tanto a causas antrópicas, intencionada, como a 
procesos naturales asociados a la destrucción del poblado, probablemente, por una crecida del río. De ser correcta la interpretación sobre su posición original, en una oquedad de la roca toba, visible para las gentes del asentamiento prehistórico, y la asociación de estas formaciones a fuentes de aguas de calidad, lleva a presuponer la posibilidad de que la deposición de esta vasija sobre un manantial, bien como referente de algún tipo de ritual, de ofrenda para purificar o garantizar el acceso y calidad del recurso hídrico o evidencia de algún acto de socialización, significación, relacionado con ello.

Es evidente que en esta etapa, hay que considerar la utilización de la cerámica como soporte para expresar o trasladar símbolos o mensajes más o menos codificados. Ya se propuso el uso simbólico de determinadas reproducciones gráficas sobre cerámica en aquellos espacios carentes de los soportes tradicionales en el interior meseteño: las cuevas y los abrigos (Fernández Moreno: 2013: 211-214). Al respecto se ha puesto de relieve que en las cerámicas Ciempozuelos se han identificado motivos figurados como soles, ciervos y antropomorfos a semejanza de los reproducidos en cerámicas neolíticas y calcolíticas, así como determinados motivos geométricos de las placas megalíticas peninsulares, y algunas piezas del ámbito europeo (Bueno et alii,. 2017: 333-335; Fig. 5 y 6). Muchos de estos paralelos pueden rastrearse a lo largo de la Edad del Bronce. Así pueden identificarse los mismos motivos figurados, tanto en grupos en los que la incisión es minoritaria si no ausente: Galería del Silo en la Sierra de Atapuerca (Apellaniz y Domingo, 1987: 238241; Ortega y Martín, 2012: 121, 133) como en los del Calcolítico Final-Edad del Bronce hasta la fase formativa o clásica de Cogotas I (Rodríguez Marcos, 2008: Fig. 85,1; Blanco 2014: Fig. 8 A4, A7; Delibes et alii, 1990: Fig. 11, 16; 16, 3). En lo que respecta a los motivos incisos, la similitud se repite entre los esquemas megalíticos europeos y los campaniformes (Bueno et alii, 2017: 337; Fig. 7; López et alii, 2010; Fig. 6 a 9; Poggiani et alii, 2016: 34-35, p. e., stele 30) y de nuevo se reconocen entre los esquemas Protocogotas y Cogotas I tanto de motivos incisos como excisos (Jimeno, 1984: Fig. 144 y150; Rodríguez Marcos, 2008: Fig. 202-204; Blanco, 2014: A1; Delibes et alii, 1990: Fig. 16 y 17). Y esta práctica no debió de alcanzar sólo a la cerámica, sino probablemente, por la técnica y motivos resultantes, a útiles o adornos perecederos -hueso o madera- y metálicos, como demuestran, por ejemplo, los motivos grafiados en los brazaletes del depósito de Malassis (Cher) adscrito a la fase plena final del Grupo Duffaits. Todo ello apunta a una tradición simbólica que con distintas variantes y, probablemente, modas, permanece desde el IV al I milenio AC. 


\section{CONCLUSIONES}

Por las evidencias documentadas nos encontramos ante los restos de un asentamiento de la plenitud de la Edad del Bronce, probablemente abandonado al destruirse por algún episodio de arroyada e inundación del río Duero: se constata la amortización de las estructuras identificadas por una potente capa de limos de sedimentación arrastrados una potente arroyada.

El interés y recurrencia por la ocupación de un mismo solar por grupos tan distintos, alejados en lo temporal, sólo puede explicarse por la existencia de recursos naturales de alto interés. Considerando que los edáficos son similares en toda la vega circundante y que el sitio adolece de las más mínimas condiciones de control, protección y seguridad, solo cabe suponer un interés por algún manantial o fuente al que habitualmente se asocian las formaciones calcáreas de toba, como la reconocida en la excavación. Las aguas calcáreas, fuertes, se caracterizan por abundancia de minerales que pueden ser beneficiosos para el organismo, los cultivos o para la transformación/tratamiento de productos. Al respecto, ciertas referencias señalan su interés para la producción de cerveza, en cuyo procesado dependiendo del grado de dureza - bajaría la acidez y aportaría dulzura, lo que pudo derivar en un interés por controlar su acceso y explotación.

La localización de la cazuela profusamente decorada sobre una oquedad de la toba pudiera inferir una función ritual sobre el propio recurso o bien para la identificación del grupo propietario del mismo. Los esquemas decorativos utilizados son habituales en elementos simbólicos desde el IV milenio, por lo que sin poder penetrar en su significado, sí parecen corresponder a un código de comunicación comprensible para aquellas gentes, y que a nosotros se nos escapa.

El conjunto de evidencias descubiertas en El Hocino son compatibles con las de un pequeño poblado, granja o alquería que contara con una serie de estructuras de almacenaje y en el que se realizaran actividades al aire libre, como evidencian los restos de hogares. Por su parte, las huellas de postes no permiten concretar la estructura que delimitaron o sustentaron, pero confirman el asentamiento de un grupo humano en el lugar. No es posible, por lo limitado de los hallazgos, evaluar el tamaño y duración de la ocupación, si bien la uniformidad de las estructuras y los materiales son evidentes.

Cronológicamente, los paralelos de la cazuela, el resto de las cerámicas decoradas y los pocos perfiles identificados no permiten una mayor precisión que su adscripción a la etapa Cogotas I. La presencia de las técnicas excisas, boquique e incisas en la cazuela harían suponer su encuadre en la fase clásica (1450-1200 cal AC) si bien no hay indicios para no suponerla adscrita a la fase Protocogotas (1800-1450 cal AC). Como se ha argumentado, la aparición de 
estas técnicas, a la luz de los datos disponibles, no se vincularía a la llegada, ya en la fase de plenitud, de estímulos o modelos foráneos.

Se hace necesario, a nuestro entender, separar la evolución del Grupo Cogotas I a la asociación de las técnicas decorativas y profundizar en su análisis desde la comparación de los contextos y de las relaciones tipológicas y decorativas del conjunto de sus cerámicas, que apuntan a una amplia tradición que adquiere particularidades identitarias de otras de grupos locales y una constante transformación formal y decorativa, sin que de ello derive una necesaria transformación estructural, social, de los diferentes grupos que las utilizan.

Finalmente, el resultado de la intervención arqueológica refuerza la necesidad de realizar controles de todos los movimientos de tierra en los yacimientos. Los procesos deposicionales, mal conocidos y menos estudiados, pueden producir ocultamiento o enmascarar vestigios o indicios que sólo son verificables mediante la realización de sondeos puntuales, excavaciones, más o menos extensas y, siempre, con el control de los movimientos de tierra. En esto, nunca, menos es más.

\section{BibLIOGRAFÍA}

Abarquero Moras, Francisco Javier (2005): Cogotas I. La difusión de un tipo cerámico durante la Edad del Bronce. Valladolid: Junta de Castilla y León, Arqueología de Castilla y León, Monografías, 4.

Abarquero Moras, Francisco Javier, Blanco González, Antonio Esparza Arroyo, Ángel, Rodríguez Marcos, José Antonio (2013): "The Central Iberian Meseta at the time of the Thera eruption: an overview". Tangungen des Landesmuseums für Vorgeschichte Halle, Band 9: 316-326.

Alonso, Carmen y Jiménez, Javier (2012): “El tránsito Protocogotas/CogotasI Pleno en el límite nuclear: análisis comparativo de tres yacimientos del Arlanzón (Burgos); en J. A. Rodríguez Marcos y J. Fernández Manzano (eds.): Cogotas I: una cultura de la Edad del Bronce en la Península Ibérica. Valladolid: Universidad de Valladolid: 397-408.

Álvarez, Pedro y Pérez Arrondo, Carlos Luis (1987): La cerámica excisa de la Primera Edad del Hierro en el Valle Alto y Medio del Ebro, Instituto de Estudios Riojanos, Historia, 8. 
Apellániz, J. M. y Domingo Mena, S. (1987): Estudios sobre Atapuerca (Burgos). II Los materiales de superficie del Santuario de la Galería del Silex. Cuadernos de Arqueología de Deusto, 10, Bilbao.

Bellido Blanco, Antonio (1996): Los campos de hoyos. Inicio de la economía agrícola en la Submeseta Norte. Valladolid: Universidad de Valladolid, Studia Archaeologica 85.

Blanco González, Antonio (2011): "Práctica social, memoria y ritual en Cogotas I: esbozo teórico para un enfoque renovado". Trabajos de Prehistoria, 68, 1, pp. 123-146.

Blanco González, Antonio (2014): "Sitios en altura y vasijas rotas: reconsiderando la etapa de "plenitud" de Cogotas I (1450-1150 cal AC) en la Meseta”. Trabajos de Prehistoria, 71, 1, pp. 305-329.

Blanco González, Antonio (2015): “Emulación decorativa y cerámicas ancestrales, posibles fuentes de inspiración de las alfareras meseteñas de la Edad del Bronce”. Zephyrus, LXXVI, pp. 39-56.

Bueno Ramírez, Primitiva, Barroso, Rosa y Balbín Behrmann, Rodrigo de (2017): "Redefining Ciempozuelos. Bell-Beaker Culture in Toledo". En V. S. Gonçalves (Ed): Sinos e taças. Junto ao Oceano e mais longe. Aspectos da presença campaniforme na península ibérica. Lisboa: Centro de Arqueologia da Universidad de Lisboa. Estudios \& Memorias, 10, pp. 327-341.

Casa Martínez, Carlos de la (1992): Las necrópolis medievales en la provincia de Soria. Junta de Castilla y León. Valladolid: Diputación Provincial de Soria, Asociación Española de Arqueología Medieval.

Delibes, Germán (1978): “Una inhumación triple de facies Cogotas I en San Román de Hornija (Valladolid)”. Trabajos de Prehistoria, 35, pp. 255-250.

Delibes, Germán y Fernández Manzano, Julio (1981): “El castro protohistórico de La Plaza en Cogeces del Monte (Valladolid)”. BSAA, XLVII, pp. 51-70.

Delibes, Germán, Fernández Manzano, Julio y Rodríguez Marcos, José Antonio (1990): “Cerámica de la plenitud Cogotas I: el yacimiento de San Román de Hornija (Valladolid)”. BSAA, 56, pp. 64-105.

Delibes, Germán y Fernández Miranda, Manuel (1990): “Aproximación a la cronología del grupo Cogotas I”; Zephyrus, $X X X I X-X L$, pp. 17-30.

Delibes, Germán, Romero, Fernando y Abarquero, Francisco Javier (2000): “Cerámicas excisas de discutible filiación Cogotas I en el Bronce Tardío de la Península 
Ibérica: Una taza de estilo Duffaits procedente de la cueva del Asno (Los Rábanos, Soria)”. Soria Arqueológica, 2, pp. 97-130.

Díaz del Río, Pedro (2001): La Formación del Paisaje Agrario: Madrid en el III y II milenios AC. Madrid: Comunidad de Madrid.

Díaz del Río, Pedro (2009): “Algunos usos de la comparación en la interpretación de los recintos de fosos de la Edad del Cobre”. En Actas de las cuartas jornadas de Patrimonio Arqueológico en la Comunidad de Madrid. Madrid: Dirección General de Patrimonio Histórico, Comunidad de Madrid: pp. 233-239.

Eiroa García, Jorge Juan (1980): La Cueva del Asno, Los Rábanos (Soria), campañas 1976-1977; Excavaciones Arqueológicas en España, 107.

Esparza Arroyo, Ángel Velasco, Javier y Delibes, Germán (2012): “HUM 2005-00139: Planteamiento y primeros resultados de un proyecto de investigación sobre la muerte en Cogotas I”. En J. A. Rodríguez Marcos y J. Fernández Manzano (eds.): Cogotas I: una cultura de la Edad del Bronce en la Península Ibérica. Valladolid: Universidad de Valladolid, pp. 259-320.

Fabián, García, José Francisco (2012): "Proto-Cogotas I en el sureste de la Meseta Norte. Dos facies alfareras en territorios inmediatos”. En J. A. Rodríguez Marcos y J. Fernández Manzano (eds.): Cogotas I: una cultura de la Edad del Bronce en la Península Ibérica. Valladolid: Universidad de Valladolid, pp. 323-348.

Fernández Moreno, José Javier (1986): "Cerámica de El Redal en el Museo Numantino”. En Actas del II Coloquio sobre Historia de La Rioja, Tomo I, Logroño, pp. 55-72.

Fernández Moreno, José Javier (2013): El Bronce Antiguo en el Alto Duero: Los poblados del Parpantique de Balluncar y Los Torojones de Morcuera (Soria). Valladolid: Universidad de Valladolid, Studia Archaeologica, 98.

Fernández Moreno, José Javier y Jimeno Martínez, Alfredo (1992): “Los Arenales de Rioseco (Soria): Consideraciones sobre la relación de cerámicas campaniformes y Cogotas I”. En Actas del $2^{\circ}$ Symposium de Arqueología Soriana, Colección temas Sorianos, 20. Soria: Diputación Provincial de Soria, pp. 211-229.

Fernández-Posse y de Arnaiz, María Dolores (1979): “Informe de la primera campaña (1977) en la cueva de Arevalillo (Segovia)”. Noticiario Arqueológico Hispánico, VI, 1-3, pp. 53-87.

Fernández-Posse y de Arnaiz, María Dolores (1981): "La cueva de Arevalillo (Segovia)”. Noticiario Arqueológico Hispánico, 12, pp. 45-84. 
Fernández-Posse y de Arnaiz, María Dolores (1982): “Consideraciones sobre la técnica de Boquique”. Trabajos de Prehistoria, 39, pp. 137-159.

Fernández-Posse y de Arnaiz, María Dolores (1986-1987): “La cerámica decorada de Cogotes I”. Zephyrus XXXIX-XL, pp. 231-237.

Fernández-Posse y de Arnaiz, María Dolores (1998): La investigación prehistórica en la Meseta y Galicia. Madrid: Síntesis.

Ferreiro Padín, Evelio (1991): Mapa geológico de España, escala 1:50.000: Almazán (Hoja 406).

García-Soto, Ernesto y Moure, Alfonso (1984): "Los grabados esquemáticos de San Bartolomé de Ucero (Soria)”. En Actas del I Symposium de Arqueología Soriana, Colección temas Sorianos, 9, Soria: Diputación Provincial de Soria, pp. 151-167.

Garrido Pena, Rafael (2000): El Campaniforme en la Meseta Central de la Península Ibérica (C. 2500-2000 AC.). BAR Internacional Series 892.

Gomez de Soto, José (1995): Le Bronze Moyen en Occident. La Culture des Duffaits et la Civilisation des Tumulus. Paris: Picard, L’âge du bronze en France 5.

Jimeno Martínez, Alfredo (1984): Los Tolmos de Caracena (Soria) Nuevas bases para el estudio de la Edad del Bronce en la Zona del Alto Duero. Excavaciones Arqueológicas en España, 134.

Jimeno Martínez, Alfredo (1985): “Prehistoria”. En J.A. Pérez Rioja, J. A (Dir.): Historia de Soria, Tomo I. Soria: Centro de Estudios Sorianos, pp. 85-122.

Jimeno Martínez, Alfredo y Fernández Moreno, José Javier (1991): Los Tolmos de Caracena. Aportación al Bronce Medio Meseteño. Excavaciones Arqueológicas en España, 161.

Jimeno Martínez, Alfredo y Fernández Moreno, José Javier (1985): “Los Quintanares de Escobosa de Calatañazor (Soria). Algunos aspectos sobre la transición de la Edad del Bronce a la del Hierro”. RICUS, IX, 3, pp. 49-63.

Jimeno Martínez, Alfredo y Fernández Moreno, José Javier (1992): “El poblamiento desde el Neolítico a la Edad del Bronce: constantes y cambios”. En Actas del $2^{\circ}$ Symposium de Arqueología Soriana, Colección temas Sorianos, 20. Soria: Diputación Provincial de Soria, pp. 69-101.

López, Joan B., Moya, Andreu, Escala, Oscar y Nieto, Ariadna (2010): "La cista tumulària amb esteles esculpides dels Reguers de Serós (Artesa de Segre, Lleida): una aportació insòlita dins de l'art megalític peninsular i europeu”. Tribuna d’Arqueologia 2008-2009, pp. 87-125. 
Martín Benito, José Ignacio y Jiménez González, Manuel Carlos (1988-89): “En torno a una estructura constructiva en un "campo de hoyos” de la Edad del Bronce en la Meseta Española (Forfoleda, Salamanca)”, Zephyrus, XLI-XLII, pp. 263-281.

Martín Valls, Ricardo y Delibes de Castro, Germán (1976): "Sobre la cerámica de Cogotas I”. BSAA, XLII, pp. 5-18.

Martín Valls, Ricardo y Delibes de Castro, Germán (1989): La cultura del vaso campaniforme en las campiñas meridionales del Duero. El enterramiento de Fuente Olmedo (Valladolid). Valladolid: Museo Arqueológico de Valladolid, Monografías del Museo Arqueológico de Valladolid, 1.

Martínez Díez, Gonzalo (1983): Las comunidades de Villa y Tierra de la Extremadura Castellana, Madrid.

Molina, Fernando y Arteaga, Oswaldo (1976): "Problemática y diferenciación en grupos de la cerámica con decoración excisa en la Península Ibérica”. Cuadernos de Prehistoria de la Universidad de Granada, 1, pp. 175-214.

Moral, Sergio y Navazo, Marta (2006-2007): "Revisión y nuevas aportaciones sobre el poblamiento prehistórico en el cañón del río Lobos (Soria-Burgos)”. BSAA, LXXII-LXXIII, pp. 39-65.

Moral, Sergio, Rodríguez Marcos, José Antonio y Fernández Lomana, Juan Carlos (2003/2004): "Las cerámicas de la cueva de El Mirador (Ibeas de Juarros, Burgos) en el contexto del Bronce Medio de la Sub-meseta Norte”, BSAA, LXIX-LXX, pp. 57-74.

Ortega, Ana Isabel y Martín, Miguel Ángel (2012): Cuevas de Atapuerca. Una visión de la mano del grupo espeleológico Edelweiss. Burgos: Diputación Provincial de Burgos y Grupo Edelweiss.

Picazo Millán, Jesús Vicente (1993): La Edad del Bronce en el Sur del Sistema Ibérico Turolense, I: Los Materiales Cerámicos. Teruel: Monografía Arqueológicas del S.A.E.T., 7.

Poggiani Keller, Raffaela, Curdy, Fhilippe, Ferroni, Matteo y Sarti, Lucia (2016): Area megalitica Sain-Martin-de-Corl'eans, parco archeologico e museo. Guida breve; Regione Autonoma Valle D’Aosta. Documento pubblicato da 12vda.it, quotidiano on line della Valle d'Aosta, consultado en enero 2019.

Revilla Andía, María Luisa (1985): Carta Arqueológica de Soria. Tierra de Almazán. Soria: Diputación Provincial de Soria. 
Rodríguez Marcos, José Antonio (2008): Estudio secuencias de la Edad del Bronce en la Ribera del Duero (Provincia de Valladolid). Valladolid: Junta de Castilla y León, Arqueología en Castilla y León, Monografías, 7.

Rodríguez Marcos, José Antonio (2012): “Algunas notas acerca del proceso formativo de la cultura Cogotas I”. En J.A. Rodríguez Marcos y J. Fernández Manzano (eds.): Cogotas I: una cultura de la Edad del Bronce en la Península Ibérica. Valladolid: Universidad de Valladolid, pp. 147-164.

Rodríguez Marcos, José Antonio y Fernández Manzano, Julio (eds.) (2012): Cogotas I: una cultura de la Edad del Bronce en la Península Ibérica. Valladolid: Universidad de Valladolid.

Rodríguez Marcos, José Antonio y Palomino, Ángel L. (1997): “Un asentamiento castreño del Bronce Antiguo en la cuenca del Duero: El Pico Romero de Santa Cruz de la Salceda (Burgos)”. En R. de Balbín y P. Bueno (Eds.): Actas del II Congreso de Arqueología Peninsular, t. II. Neolítico, Calcolítico y Bronce; Zamora, pp. 579-591.

Romero, Fernando y Delibes, Germán (1978): "Un vaso inciso de la Edad del Bronce hallado en Calatañazor”. Celtiberia, 56, pp. 306 y ss.

Rosa Municio, Rafael de la (1995): "El Balconcillo de Ucero y su datación en el contexto de la Edad del Bronce de la Meseta”. Complutum, 6, pp. 193-201.

Ruiz Zapatero, Gonzalo (1984): “Cogotas I y los primeros Campos de Urnas en el Alto Duero". En Actas del I Symposium de Arqueología Soriana; Colección temas Sorianos, 9, Soria: Diputación Provincial de Soria, pp. 169-184.

Samaniego, Blanca; Jimeno, Alfredo; Fernández, José Javier y Gómez, Juan Antonio (2001): Cueva Maja (Cabrejas del Pinar. Soria) Espacio y simbolismo en los inicios de la Edad del Bronce. Valladolid: Junta de Castilla y León, Arqueología en Castilla y León, Memorias 10.

Vergès, Josep $\mathrm{M}^{\mathrm{a}}$, Allue, Ethel, Angelucci, Diego E.; Cebriá, Artur, Díez, Carlos, Fontanals Marta, Manyanos, Antoni, Montero, Sonsoles, Moral, Sergio, Vaquero, Manuel y Zaragoza, Josep (2002): "La Sierra de Atapuerca durante el Holoceno: datos preliminares sobre las ocupaciones de la edad del Bronce en la Cueva del Mirador (Ibeas de Juarros, Burgos)”. Trabajos de Prehistoria, 59, 1, pp. 107-122. 